\title{
Preferential proton conduction along a three-dimensional dopant network in yttrium-doped barium zirconate: A first-principles study
}

\author{
$\operatorname{AUTHOR}(\mathrm{S}):$ \\ Toyoura, Kazuaki; Meng, Weijie; Han, Donglin; Uda, \\ Tetsuya
}

\section{CITATION:}

Toyoura, Kazuaki ... [et al]. Preferential proton conduction along a three-dimensional dopant network in yttrium-doped barium zirconate: A first-principles study. Journal of Materials Chemistry A 2018, 6(45): 22721-22730

\section{ISSUE DATE:}

2018-10-18

URL:

http://hdl.handle.net/2433/235614

\section{RIGHT:}

This is the accepted manuscript of the article, which has been published in final form at

https://doi.org/10.1039/C8TA08283A.; The full-text file will be made open to the public on 18 October 2019 in

accordance with publisher's 'Terms and Conditions for Self-Archiving'; This is not the published version. Please cite only the published version.; この論文は出版社版でありません。引用の際には出版社版をご確認ご利用ください。 


\title{
Preferential Proton Conduction along Three-Dimensional Dopant Network in Yttrium-Doped Barium Zirconate: A First-Principles Study
}

Kazuaki Toyoura, * Weijie Meng, Donglin Han, and Tetsuya Uda Department of Materials Science and Engineering, Kyoto University, Yoshida, Sakyo, Kyoto 606-8501, Japan.

* Electronic address: toyoura.kazuaki.5r@kyoto-u.ac.jp

\begin{abstract}
The atomic-scale picture of the proton conduction in Y-doped $\mathrm{BaZrO}_{3}$ has theoretically been investigated using first-principles calculations on the basis of the nudged elastic band (NEB) method and the kinetic Monte Carlo (KMC) method. In this crystal, protons mainly reside around Y dopants due to the electrostatic attractive interaction between dopants and protons, which is well-known as proton trapping. In the case of the typical doping level $x \sim 0.2$ in $\mathrm{BaZr}_{1-x} \mathrm{Y}_{x} \mathrm{O}_{3-\delta}$, the existence of $\mathrm{Y}-\mathrm{Y}-\mathrm{Y}$ triplets with the triangular configuration is an origin of the strong proton-trapping effect, in which protons are oscillatorily transferred between two adjacent sites. The proton conduction behavior is however different from the conventional picture of trapping \& detrapping applicable only to the case of dilute doping. At the typical doping level with dense dopants, protons preferentially migrate along the three-dimensional network of $\mathrm{Y}$ dopants throughout the crystal without detrapping. The preferential conduction pathways moderate the strong trapping effect by dense dopants, resulting in the minor reduction of the proton diffusivity and mobility in highly-doped $\mathrm{BaZrO}_{3}$.
\end{abstract}

\section{Keywords}

Preferential proton conduction, Proton trapping, Ab-initio, Nudged elastic band method, Kinetic Monte Carlo method 


\section{Introduction}

Proton-conducting oxides have attracted attention due to their potential application to electrolytes in various electrochemical devices, such as fuel cells and water electrolyzers [1-6]. Perovskite-type oxides are a promising class of proton-conducting oxides, among which acceptor-doped barium zirconate $\mathrm{BaZrO}_{3}$ with the cubic perovskite structure is a leading candidate with both high proton conductivity and excellent chemical stability [7-11]. The reported proton conductivity is greater than $1 \times 10^{-2} \mathrm{~S} / \mathrm{cm}$ at $873 \mathrm{~K}$, indicating the possible application for intermediate temperature fuel cells.

In general, protons are incorporated into oxide crystals as charge carriers by aliovalent doping according to the charge compensation mechanism. Taking Y-doped $\mathrm{BaZrO}_{3}$ for example, a part of $\mathrm{Zr}^{4+}$ ions are substituted by $\mathrm{Y}^{3+}$ ions, to form $\mathrm{Y}^{\prime} \mathrm{Zr}$ with negative charges. Interstitial protons are possible defects to cancel out the negative charges of $\mathrm{Y}^{\prime} \mathrm{Zr}$, which are dominant under high water vapor pressures at low temperatures [12-14]. The solubility of dopants in $\mathrm{BaZrO}_{3}$ is comparatively high, e.g., $x \sim 0.3$ in $\mathrm{BaZr}_{1-x} \mathrm{Y}_{x} \mathrm{O}_{3-\delta}[15,16]$. This is one of key factors for the high proton conductivity, as well as the high proton mobility in the crystal $[3,7,17]$.

On the other hand, such aliovalent dopants have a negative effect on the proton conductivity, well known as proton trapping due to dopant-proton association [18]. Yamazaki et al. addressed the quantitative evaluation of the proton trapping effect on the proton conductivity of $\mathrm{BaZr}_{0.8} \mathrm{Y}_{0.2} \mathrm{O}_{3-\delta}$ by simply assuming two types of protons in the crystal, i.e., free and trapped protons. In their report, the temperature dependence of the measured proton diffusivity was fitted on the basis of the simple assumption, to divide the apparent activation energy of the diffusivity $(Q \sim 45$ $\mathrm{kJ} / \mathrm{mol}=0.47 \mathrm{eV}$ ) into two contributions, i.e., the potential barrier for the proton diffusivity without trapping $\left(E_{\mathrm{a}} \sim 0.16 \mathrm{eV}\right)$ and the association energy of dopants and protons $\left(E_{\mathrm{as}} \sim 0.29 \mathrm{eV}\right)$.

Note that the simple assumption does not correctly describe the atomic-scale picture of proton diffusion in the crystal, although it may be a good approximation in the case of dilute doping [19-21]. In general, there are many types of proton sites in the crystal depending on the local 
configurations of adjacent dopants, even though all proton sites are crystallographically equivalent in the dopant-free situation. At the typical doping level $x \sim 0.2$ in $\mathrm{BaZr}_{1-x} \mathrm{Y}_{x} \mathrm{O}_{3-\delta}$, the dense $\mathrm{Y}$ dopants should make a complicated situation with a few dozen proton sites at least, meaning that the single $E_{\text {a }}$ and $E_{\text {as }}$ cannot be defined in the rigorous manner. It is thus difficult to quantitatively evaluate the proton trapping from macroscopic information acquired by most of experiments.

Theoretical calculations are powerful tools for fundamental understanding of the proton trapping in the atomic level. According to the literature based on first-principles calculations $[3,7,17,22-25]$, protons in the $\mathrm{BaZrO}_{3}$ crystal reside around $\mathrm{O}$ ions with forming an $\mathrm{OH}$ bond, and migrate over a long range by repeating the rotation around single $\mathrm{O}$ ions and hopping between neighboring $\mathrm{O}$ ions (rotation and hopping mechanism). Figure 1 shows the reported potential energy surface (PES) of a proton in the perfect $\mathrm{BaZrO}_{3}$ crystal without dopants [26]. There are four equivalent energy global minima around an $\mathrm{O}$ ion, which are connected by a single type of rotation paths with a low potential barrier. In addition, these rotational orbits are overlapped with adjacent orbits, corresponding to the hopping paths. The calculated potential barriers of the rotation and hopping paths are reported to be $0.18 \mathrm{eV}$ and $0.25 \mathrm{eV}$, respectively. The difference in the potential barrier between the proton rotation and hopping means that the hopping path is the rate-determining process for the proton diffusion in the perfect crystal.

The change in the proton PES by several types of dopants has also been evaluated theoretically in a first-principles manner [22-25]. In the literature, the changes in the site energy and the potential barriers of proton migration were evaluated in a supercell with a single or a few $\mathrm{Zr}$ ions substituted by dopants. In the case of $\mathrm{Y}$ dopants, the calculated proton site energies are different by $\sim 0.2 \mathrm{eV}$ depending on the $\mathrm{Y}$ local configuration, and the calculated potential barriers of the rotation and hopping paths are largely scattering in the range of $0.1-1.0 \mathrm{eV}$. These results clearly indicate that the aforementioned simple assumption is insufficient for quantitative evaluation of the proton trapping in highly-doped $\mathrm{BaZrO}_{3}$. 
However, there are several concerns in these theoretical studies, in which small supercells consisting of $3 \times 3 \times 3$ or $2 \times 2 \times 2$ unit cells were employed, and only a few local configurations of Y dopants were taken into consideration. In addition, the dopant configuration is assumed to be random in their subsequent diffusion simulations based on the kinetic Monte Carlo (KMC) method [27], although the formation of Y-Y pairs is reported to be favorable energetically [28]. The proton trapping effect is therefore revisited in the present study using larger supercells of $4 \times 4 \times 4$ unit cells with a variety of Y configurations. In the diffusion simulations based on the KMC method, much larger supercells of $10 \times 10 \times 10$ unit cells were used, in which $\mathrm{Y}$ dopants are randomly arranged in the form of "single Y ions" or "Y-Y pairs" to confirm the effect of Y-Y association. These two configurations are called "random configuration" and "adjacent configuration", hereafter.

\section{Computational procedures}

The proton diffusivity and conductivity of Y-doped $\mathrm{BaZrO}_{3}$ were evaluated by taking a two-step approach in the present study. First, the energy profiles along the rotation and hopping paths were evaluated in a first-principles manner based on the nudged elastic band (NEB) method $[29,30]$ for various local configurations of $\mathrm{Y}$ dopants on $\mathrm{Zr}$ sites around the paths. Then, the diffusion simulations were performed on the basis of the KMC method using the mean jump frequencies estimated from the calculated potential barriers of all paths at the first step.

The NEB calculations were performed using first-principles calculations on the basis of the projector augmented wave (PAW) method as implemented in the VASP code [31-36]. The $5 s, 5 p, 6 s$ and $5 d$ orbitals for $\mathrm{Ba}, 4 s, 4 p, 5 s$ and $4 d$ orbitals for $\mathrm{Zr}$ and $\mathrm{Y}, 2 s$ and $2 p$ orbitals for $\mathrm{O}$, and $1 s$ orbital for $\mathrm{H}$ were treated as valence states in the PAW potentials. The generalized gradient approximation (GGA) parameterized by Perdew, Burke, and Ernzerhof was used for the exchange-correlation term [37]. The plane wave cutoff energy was set to $400 \mathrm{eV}$. A supercell consisting of $4 \times 4 \times 4$ unit cells of $\mathrm{BaZrO}_{3}$ (320 atoms) was used with a single $k$-point sampling at the $\Gamma$ point. A proton and several $\mathrm{Y}$ dopants were additionally introduced into the supercell as $\mathrm{OH}_{\mathrm{O}}$ 
and $\mathrm{Y}_{\mathrm{Zr}}^{/}$, respectively. A uniform background charge was introduced to neutralize the supercell in case that there is a net charge of defect species.

Several adjacent $\mathrm{Zr}$ sites around the rotation and hopping paths were taken into consideration for Y local configurations, as shown in Fig. 2. Specifically, two first-nearest-neighbor (1NN) Zr sites (R1 and R2) and four 2NN (R3-R6) are considered for the rotation path, and one 1NN (H1), two 2NN (H2 and H3), and one 3NN (H4) are for the hopping path. The distances from the rotation and hopping paths are here defined as those from the middle points of the two paths. The total numbers of irreducible $\mathrm{Y}$ configurations are 24 and 12 for the rotation and hopping, respectively (See Tables 1 and 2 for details). The initial and final states for each path were first determined by structural optimizations, and the migration trajectory connecting the two states and their energy profiles were then evaluated by the NEB method. The atomic positions were fully optimized until the atomic forces (including the spring forces in the NEB calculations) were converged to be less than $0.02 \mathrm{eV} / \AA$.

Proton diffusion simulations were subsequently performed on the basis of the KMC method using all of the rotation and hopping paths with a variety of $\mathrm{Y}$ configurations. Based on the transition state theory [38], the mean frequency of the proton jump along each path, $v$, is given by

$$
v=v_{0} \exp \left(-\Delta E^{\mathrm{mig}} / k_{\mathrm{B}} T\right)
$$

where $v_{0}$ is the vibrational prefactor, $\Delta E^{\mathrm{mig}}$ is the potential barrier for the proton jump, $k_{\mathrm{B}}$ is the Boltzmann constant, and $T$ is the temperature. $v_{0}$ was set to $10 \mathrm{THz}$ for all of the migration paths, which is a typical value for ionic jumps in crystals [19-21,39,40]. A supercell consisting of $10 \times 10 \times 10$ unit cells $(1,000 \mathrm{Zr}$ sites $)$ was used for the KMC simulations, in which a part of $\mathrm{Zr}$ ions were substituted by $\mathrm{Y}$ ions according to a given $\mathrm{Y}$ concentration $x \mathrm{Y}\left(=x\right.$ in $\mathrm{BaZr}_{1-x} \mathrm{Y}_{x} \mathrm{O}_{3-\delta}$, in the range $0-0.3$. In the supercell, $\mathrm{Zr}$ ions were randomly substituted by single $\mathrm{Y}$ ions or $\mathrm{Y}-\mathrm{Y}$ pairs to evaluate the effect of $\mathrm{Y}-\mathrm{Y}$ association on the proton diffusivity. The KMC simulations of a single proton were repeatedly performed (1,000 times) at each temperature in the range $600-1000 \mathrm{~K}$. The proton diffusivity $D$ was estimated by the definitional equation, 


$$
D=\lim _{n \rightarrow \infty}<\mathbf{r}_{n}^{2} / 6 t_{n}>,
$$

where $\mathbf{r}_{n}$ and $t_{n}$ are the displacement vector and the time after $n$-times KMC steps, respectively, and $<>$ denotes the ensemble mean. The KMC step, $n$, was set by carefully checking the convergence of the diffusivity at each temperature. The proton diffusivity at a given $x_{\mathrm{Y}}$ was estimated as the average in 10 supercells with different $\mathrm{Y}$ configurations. The proton mobility, $\mu$, was then obtained by the Nernst-Einstein equation, $\mu=e D / k_{\mathrm{B}} T$, and the proton conductivity, $\sigma$, was finally estimated from the product of the charge, $e$, the concentration, $c$, and the mobility, $\mu$.

\section{Results and Discussion}

\subsection{Potential barriers for proton rotation and hopping}

All the calculated $\Delta E^{\mathrm{mig}}$ of the rotation and hopping paths with various $\mathrm{Y}$ configurations are listed in Tables 1 and 2 . The calculated $\Delta E^{\mathrm{mig}}$ are widely scattering with reference to those in the dopant-free situation (paths R0-1 and H0-1). Specifically, the $\Delta E^{\mathrm{mig}}$ for proton rotation and hopping are in the range of $0.08-1.08 \mathrm{eV}$ and $0.02-0.56 \mathrm{eV}$, respectively.

The two $\Delta E^{\mathrm{mig}}$ of forward and backward migrations $\left(\Delta E_{\mathrm{i} \rightarrow \mathrm{f}}^{\mathrm{mig}}\right.$ and $\left.\Delta E_{\mathrm{f} \rightarrow \mathrm{i}}^{\mathrm{mig}}\right)$ are basically different when the initial and final sites are inequivalent. Figure 3 shows the differences in potential barrier between the forward and backward migrations $\left(\Delta E_{\mathrm{i}^{\prime} \rightarrow \mathrm{f}^{\prime}}^{\mathrm{mig}}-\Delta E_{\mathrm{f}^{\prime} \rightarrow \mathrm{i}^{\prime}}^{\mathrm{mig}}\right)$ only for the paths having inequivalent initial and final states. In this figure, the initial state $i^{\prime}$ (or final state $f^{\prime}$ ) is redefined as the state surrounded by more (or less) $\mathrm{Y}$ dopants. In the case of the rotation path, sites R1 and R2 are equivalent for both initial and final states, while sites "R3 and R4" and "R5 and R6" are respectively close to the original initial and final states $\mathrm{i}$ and $\mathrm{f}$. Therefore, the difference in the number of Y dopants between the "R3 and R4" vs. the "R5 and R6" determines the redefined initial and final states i' and f'. In the same manner, the difference in the number of Y dopants at "H2" vs. "H3" determines the states $\mathrm{i}^{\prime}$ and $\mathrm{f}$ for the proton hopping. According to the simple trapping picture, more Y dopants should more stabilize protons due to the electrostatic attractive interaction between dopants and protons, resulting in the positive value in Fig. 3. Actually, all paths except a few 
hopping paths have a positive value, meaning that the simple trapping picture is qualitatively reasonable. The two exceptions imply that the proton site energies are not governed only by the number of adjacent $\mathrm{Y}$ dopants and the distances from the dopants. For example, the potential energy of a proton at the $1 \mathrm{NN}$ proton site from a $\mathrm{Y}$ dopant is reported to be slightly higher than that at the 2NN site [28], leading to the exception of path H1-2. The opposite trend is furthermore enhanced when the site $\mathrm{H} 1$ is additionally occupied by a Y dopant (path H2-1). The large distortion and tilting of $\mathrm{YO}_{6}$ octahedral units can be another key factor determining the proton site energy. Fig. 4 shows the local structures around proton sites in the initial and final states (i' and f') of path H2-1. Protons in the crystal form a single $\mathrm{OH}$ bond, which basically directs toward the middle point between the two $2 \mathrm{NN} \mathrm{O}$ ions in $\mathrm{BaZrO}_{3}$. However, some of them largely tilt toward either of the two $2 \mathrm{NN} \mathrm{O}$ ions to form a strong $\mathrm{OH}-\mathrm{O}$ bond. The final state $\mathrm{f}^{\prime}$ of path $\mathrm{H} 2-1$ is a typical example of the $\mathrm{OH}-\mathrm{O}$ bond formation, where the proton is more stabilized than that in the initial state i', leading to an exception against the simple trapping picture based on the electrostatic interaction.

Although the $\Delta E^{\mathrm{mig}}$ for the proton rotation and hopping with several Y configurations were calculated by first-principles calculations in the previous theoretical studies [24,25], only a small part of Y configurations in Tables 1 and 2 were taken into account. For example, the $\Delta E^{\mathrm{mig}}$ of three rotation paths and two hopping paths were calculated in Ref. [24], corresponding to R0-1, R1-1, R1-2, H0-1, and H1-1. Ref. [25] took a bit more Y configurations into account, i.e., three rotations and five hoppings (R0-1, R1-1, R2-1, H0-1, H1-1, H1-2, H2-1, and H3-2). Figure 5 shows the classification of all paths in Tables 1 and 2 into the eight paths in Ref. [25] on the basis of the Y local configurations. Specifically, the $\Delta E^{\mathrm{mig}}$ of the rotation path in Ref. [25] is given by a function of the Y configuration only at the two $1 \mathrm{NN}$ sites (R1 and R2), while it is expressed as a function of the $\mathrm{Y}$ configuration at the six sites $(\mathrm{R} 1-\mathrm{R} 6)$ in the present study. The classification of the rotation paths in Fig. 5 is the projection from the six-dimensional function in the present study onto the two-dimensional function in Ref. [25]. The hopping paths are also classified in the same manner. Note that the paths $\mathrm{H} 1-2$ and $\mathrm{H} 2-1$ have two $\Delta E^{\mathrm{mig}}$ for the forward and backward migrations, 
leading to ten groups in total. The classified $\Delta E^{\mathrm{mig}}$ are scattering in each group, indicating that more Y configurations should have been necessary to evaluate the effect of $\mathrm{Y}$ dopants on the proton diffusivity in the literature. In addition, the reported $\Delta E^{\mathrm{mig}}$ of paths H2-1 and H3-2 are considerably overestimated in comparison with our results, probably due to the smaller supercell of $2 \times 2 \times 2$ unit cells in Ref. [25]. The structural relaxation during the proton migration could be excessively restricted in the small supercell with the periodic boundary condition.

\subsection{Proton diffusivity and conductivity}

Using all information on the rotation and hopping paths with various Y configurations, the proton diffusion simulations were performed on the basis of the KMC method. Figure 6 shows the estimated diffusion coefficients as a function of inverse temperature, where single $\mathrm{Y}$ ions or Y-Y pairs are randomly arranged in a large supercell of $10 \times 10 \times 10$ unit cells (random and adjacent configurations, respectively). The black line with the solid circles in each figure shows the diffusivity without $\mathrm{Y}$ dopants, and therefore the deviation from the black line directly indicates the proton trapping effect by $\mathrm{Y}$ dopants. The proton diffusivity decreases with increasing the $\mathrm{Y}$ concentration, qualitatively meaning stronger proton trapping by more $\mathrm{Y}$ dopants. In addition, the trapping effect is rather stronger in the adjacent configuration of $\mathrm{Y}$ dopants than that in the random configuration, particularly at low Y concentration. These trends are consistent with the previous report on the trapping of point defects (oxygen vacancies and proton interstitials) in $\mathrm{BaZrO}_{3}$ [41]. In their report, more Y-Y pairs exist in the crystal with higher $\mathrm{Y}$ concentration, which cause larger distortion of the local structure in the crystal, leading to stronger proton trapping. However, the decrease in the proton diffusivity is moderate for proceeding Y-dopant clustering, e.g., one order of magnitude at most even at the highest doping level and the lowest temperature.

The black broken line in each figure shows the reported proton diffusivity in $\mathrm{BaZr}_{0.8} \mathrm{Y}_{0.2} \mathrm{O}_{3-\delta}$, measured by the AC impedance spectroscopy [18]. The estimated diffusivity in the present study is one order of magnitude higher than the reported bulk diffusivity, although the slight 
convex upward is well reproduced. A possible origin of the difference between the estimated and measured diffusivities is a given vibrational prefactor, which could be lower than the typical value $(10 \mathrm{THz})$ in this crystal. Another possible origin is the existence of other defect species, such as $\mathrm{O}$ and Ba vacancies. These two defects could have proton blocking and trapping effects, respectively, to decrease the proton diffusivity. Note that the reported experimental values are also scattering depending on the procedures of sample preparations. For example, the grain-boundary-free thin film of Y-doped $\mathrm{BaZrO}_{3}$ prepared by the pulsed laser deposition (PLD) is reported to exhibit one order of magnitude higher proton conductivity than the typical bulk conductivity of poly-crystal samples at the same doping level [9]. Thus, the estimated proton diffusivity in the present study is in reasonable agreement with the experimental values in light of the dispersion of experimental values and the difference between the computational model and the actual situation.

The single $E_{\text {a }}$ and $E_{\text {as }}$ can be extracted from the estimated diffusivity curves in the present study by fitting the curves in the same manner as in Ref. [18]. In the case of $x_{\mathrm{Y}}=0.2$, the $E_{\text {a }}$ and $E_{\text {as }}$ are 0.28 and $0.14 \mathrm{eV}$ in the random configuration, and 0.21 and $0.22 \mathrm{eV}$ in the adjacent configuration, respectively, while the reported $E_{\mathrm{a}}$ and $E_{\mathrm{as}}$ are $\sim 0.16 \mathrm{eV}$ and $\sim 0.29 \mathrm{eV}$, respectively. Although the relatively lower $E_{\text {as }}$ seems to indicate underestimation of the trapping effect in the present study, this only means the steeper slope and less curvature of the estimated diffusivities in the same temperature range. Thus, the single $E_{\mathrm{a}}$ and $E_{\text {as }}$ have no physical meaning, nothing but the fitting parameter in this case.

Figure 7 shows the estimated proton conductivities at 600 and $1000 \mathrm{~K}$ as a function of $\mathrm{Y}$ concentration (See Figs. S1 and S2 in the ESI for the detailed information). The blue and red lines correspond to the ideal and actual cases, in which the hydration degree is exactly equal to 1 and depends on the temperature due to the dehydration at high temperatures, respectively. The measured hydration degree by the Karl Fischer titration method in the literature [16] was here used in the actual case. At $600 \mathrm{~K}$, the measured hydration degree is close to 1, leading to the comparable conductivities between the ideal and actual cases. By contrast, at $1000 \mathrm{~K}$, the conductivities in the 
actual case are much lower than that in the ideal case due to the remarkable dehydration. As for the dependence on $\mathrm{Y}$ concentration, the proton conductivity monotonically increases with the $\mathrm{Y}$ concentration at $1000 \mathrm{~K}$, meaning that the increase of the carrier concentration exceeds the decrease of the proton diffusivity by Y doping. On the other hand, the estimated conductivity has a maximum around $x_{\mathrm{Y}}=0.25$ at $600 \mathrm{~K}$. The similar trend can be seen in the reported bulk conductivity of Y-doped $\mathrm{BaZrO}_{3}$ at $573 \mathrm{~K}$ measured by impedance spectroscopy [16], in which the maximum point is around $x \mathrm{Y}=0.2$.

\subsection{Proton-trapping sites}

In this subsection, the atomic-scale picture of the proton conduction in Y-doped $\mathrm{BaZrO}_{3}$ is clarified on the basis of the existence probability of a proton in the crystal during the KMC simulations. Particularly, the key Y configuration reducing the proton diffusivity and conductivity is identified in the case of the typical doping level $x_{\mathrm{Y}}=0.2$. In addition, the origin of the difference in the proton diffusivity between the random and adjacent configurations of $Y$ dopants is discussed.

Prior to understanding the atomic-scale picture of the proton conduction, 12,000 proton sites in a KMC simulation cell $(10 \times 10 \times 10$ unit cells $)$ are classified by the local configurations of $\mathrm{Y}$ dopants. Specifically, since a proton site is connected to two rotation paths and two hopping paths as shown in Fig. 8(a), all proton sites are classified by the combination of these four paths, i.e., by the $\mathrm{Y}$ local configuration at the two $1 \mathrm{NN}$, two $2 \mathrm{NN}$, and four $3 \mathrm{NN} \mathrm{Zr}$ sites from the proton site, leading to 84 types of proton sites in total. Here, they are numbered in the ascending order of the total number of Y dopants around the four paths, which is detailed in Table S1 in the ESI.

Because of stronger trapping effect at lower temperatures in principle, the KMC simulations at the lowest temperature $(600 \mathrm{~K})$ are focused on hereafter. Figure $8(\mathrm{~b})$ shows the fraction of each type of proton sites in the KMC simulation cells $r_{\text {site }}$ (blue bars) and the existence probability of a proton at each site $p_{\mathrm{H}}{ }^{+}$(red bars) during the $\mathrm{KMC}$ simulations at $x_{\mathrm{Y}}=0.2$ in the random configuration of $\mathrm{Y}$ dopants. The $r_{\text {site }}$ profile is totally different from the $p_{\mathrm{H}}{ }^{+}$profile in Fig. 
8(b), indicating the site selectivity of protons in the migrating proton. Note that the proton hardly occupies the sites surrounded by few Y dopants in spite of their high $r_{\text {site. }}$ This clearly indicates that the simple picture of proton trapping and detrapping is not applicable to the highly-doped situation, in which the proton mainly resides around $\mathrm{Y}$ dopants and preferentially migrates along the three-dimensional network of $\mathrm{Y}$ dopants throughout the crystal. The preferential conduction pathways moderate the strong trapping effect by dense dopants, resulting in the minor reduction of the proton diffusivity and mobility in the highly-doped $\mathrm{BaZrO}_{3}$.

The migrating proton particularly prefers the three proton sites (site ID: 60,61, and 63), around which the local Y configurations are shown in Figs. 9(a)-(c). These proton sites have a common Y configuration, triangular configuration of three Y dopants shown in Fig. 9(d). Note that the extremely low potential barrier of a hopping path between two adjacent proton sites, $0.05 \mathrm{eV}$. The potential barriers of the other paths connecting to the two proton sites are higher than $0.3 \mathrm{eV}$, resulting in the oscillatory proton transfer between the two sites. Thus, the Y-Y-Y triplet in the triangular configuration is a crucial $\mathrm{Y}$ configuration reducing the proton diffusivity and conductivity.

In the adjacent configuration of $\mathrm{Y}$ dopants, a few other sites also have some contribution to the proton trapping. Figure 8(c) shows the $r_{\text {site }}$ and the $p_{\mathrm{H}}{ }^{+}$during the $\mathrm{KMC}$ simulations at $600 \mathrm{~K}$ and $x_{\mathrm{Y}}=0.2$ in the adjacent configuration. The additional trapping sites (site ID: 82, 83, and 84) are surrounded by more Y dopants, which are connected to a type of hopping paths (H4-1) and two types of rotation paths (R5-2 and R6-1). The potential barriers of proton migration from these sites are comparatively high, resulting in the proton's spending a lot of time at the three sites. The existence of the additional trapping sites is thus the major origin of the stronger proton trapping in the adjacent configuration than that in the random configuration. In real samples of Y-doped $\mathrm{BaZrO}_{3}$ sintered at high temperatures, the $\mathrm{Y}$ configuration can be an intermediate state between the random and adjacent configurations. This suggests that the random distribution of Y dopants without clustering is a possible strategy to improve the proton conductivity, although the expected 
increase is a few tenths at most as is clear from the difference in the estimated conductivity between the two configurations in Fig. 7.

\section{Conclusions}

In the present study, the proton trapping effect by dopants in Y-doped $\mathrm{BaZrO}_{3}$ was theoretically revisited in the first-principles manner. The 24 rotation and 12 hopping paths with a variety of Y local configurations were evaluated by the NEB calculations, whose potential barriers are scattering in the range of $0.08-1.08 \mathrm{eV}$ and $0.02-0.56 \mathrm{eV}$, respectively. Except for a few hopping paths, protons are more stabilized at sites surrounded by more Y dopants, which qualitatively agrees with the picture based on the electrostatic attractive interaction between dopants and protons. The proton diffusivity estimated by the KMC simulations decreases with the $\mathrm{Y}$ concentration in the simulation cell, indicating that the trapping effect tends to be enhanced by more Y dopants. The estimated proton conductivity monotonically increases with the $\mathrm{Y}$ concentration at high temperatures, while the conductivity at low temperatures has a maximum point around $x_{\mathrm{Y}}=$ 0.25. The trend is in reasonable agreement with the reported bulk conductivity at $573 \mathrm{~K}$, although the estimated values were somewhat overestimated. The proton trapping effect is furthermore enhanced in the case of the adjacent configuration of $\mathrm{Y}$ dopants, in comparison with the random configuration. The Y-Y-Y triplet in the triangular configuration is identified to be the key proton-trapping configuration, in which protons are oscillatory transferred between two proton sites. In addition, other proton sites surrounded by more $\mathrm{Y}$ dopants also have some contribution to the proton trapping sites in the adjacent configuration. The proton conduction behavior is totally different from the conventional picture of trapping and detrapping. At the typical doping level with dense dopants, protons preferentially migrate along the three-dimensional network of Y dopants throughout the crystal. 


\section{Conflicts of interest}

There are no conflicts to declare.

\section{Acknowledgements}

This study was supported by Grants-in-Aid for Young Scientists (A) (Grant No. 17H04948) from the Japan Society for the Promotion of Science (JSPS) and Research Grant from Nippon Sheet Glass Foundation for Materials Science and Engineering. 


\section{References}

1 H. Iwahara, T. Esaka, H. Uchida and N. Maeda, Solid State Ion., 1981, 3-4, 359.

2 T. Norby, Solid State Ion., 1999, 125, 1.

3 K. D. Kreuer, Annu. Rev. Mater. Res., 2003, 33, 333.

4 L. Malavasi, C. A. J. Fisher and M. S. Islam, Chem. Soc. Rev., 2010, 39, 4370.

5 E. Kendrick, J. Kendrick, K. S. Knight, M. S. Islam and P. R. Slater, Nat. Mater, 2007, 6, 871.

6 O. Paschos, J. Kunze, U. Stimming and F. Maglia, J. Phys.: Condens. Matter, 2011, 23, 234110.

7 K. D. Kreuer, Solid State Ion., 1999, 125, 285.

8 Y. Yamazaki, R. Hernandez-Sanchez and S. M. Haile, Chem. Mater., 2009, 21, 2755.

9 D. Pergolesi, E. Fabbri, A. D. Epifanio, E.D. Bartolomeo, A. Tebano, S. Sanna, S. Licoccia, G.

Balestrino and E. Traversa, Nat. Mater., 2010, 9, 846.

10 D. Han, Y. Nose, K. Shinoda and T. Uda, Solid State Ion., 2012, 213, 2.

11 K. Katahira, Y. Kohchi, T. Shimura and H. Iwahara, Solid State Ion., 2000, 138, 91.

12 C. Kjolseth, L. Y. Wang, R. Haugsrud and T. Norby, Solid State Ion., 2010, 39-40, 1740.

13 C. Hiraiwa, D. Han, A. Kuramitsu, A. Kuwabara, H. Takeuchi, M. Majima and T. Uda, J. Am.

Ceram. Soc., 2013, 96, 879.

14 T. S. Bjorheim, E. A. Kotomin and J. Maier, J. Mater. Chem. A, 2015, 3, 7639.

15 Y. Yamazaki, P. Babilo and S. M. Haile, Chem. Mater., 2008, 20, 6352.

16 D. Han, N. Hatada and T. Uda, J. Am. Ceram. Soc., 2016, 99, 3745.

17 W. Munch, G. Seifert, K. D. Kreuer and J. Maier, Solid State Ion., 1997, 97, 39.

18 Y. Yamazaki, F. Blanc, Y. Okuyama, L. Buannic, J. C. Lucio-Vega, C. P. Grey and S. M. Haile, Nature Mater., 2013, 12, 647.

19 K. Toyoura, N. Hatada, Y. Nose, I. Tanaka, K. Matsunaga and T. Uda, J. Phys. Chem. C, 2012, 116, 19117.

20 N. Hatada, K. Toyoura, T. Onishi, Y. Adachi and T. Uda, J. Phys. Chem. C, 2014, 118, 29629.

21 K. Toyoura, A. Nakamura and K. Matsunaga, J. Phys. Chem. C, 2015, 119, 8480. 
22 M. E. Bjorketun, P. G. Sundell, G. Wahnstrom and D. Engberg, Solid State Ion., 2005, 176, 3035.

23 C. S. Shi, M. Yoshino and M. Morinaga, Solid State Ion., 2005, 176, 1091.

24 M. E. Bjorketun, P. G. Sundell and G. Wahnstrom, Phys. Rev. B, 2007, 76, 054307.

25 S. G. Kang and D. S. Sholl, RSC Adv., 2013, 3, 3333.

26 K. Toyoura, D. Hirano, A. Seko, M. Shiga, A. Kuwabara, M. Karasuyama, K. Shitara and I. Takeuchi, Phys. Rev. B, 2016, 93, 054112.

27 K. A. Fichthorn and W. H. Weinberg, J. Chem. Phys., 1991, 95, 1090.

28 H. Takahashi, I. Yashima, K. Amezawa, K. Eguchi, H. Matsumoto, H. Takamura and S. Yamaguchi, Chem. Mater., 2017, 29, 1518.

29 G. Henkelman, B. P. Uberuaga and H. Jónsson, J. Chem. Phys., 2000, 113, 9901.

30 G. Henkelman and H. Jónsson, J. Chem. Phys., 2000, 113, 9978.

31 P. E. Blöchl, Phys. Rev. B, 1994, 50, 17953.

32 G. Kresse and J. Hafner, Phys. Rev. B, 1993, 47, 558.

33 G. Kresse and J. Hafner, Phys. Rev. B, 1993, 48, 13115.

34 G. Kresse and J. Hafner, Phys. Rev. B, 1994, 49, 14251.

35 G. Kresse and J. Furthmüller, Comput. Mater. Sci., 1996, 6, 15.

36 G. Kresse and J. Furthmüller, Phys. Rev. B, 1996, 54, 11169.

37 J. P. Perdew, K. Burke and M. Ernzerhof, Phys. Rev. Lett., 1996, 77, 3865.

38 G. H. Vineyard, J. Phys. Chem. Solids, 1957, 3, 121.

39 R. Yu and L. C. De Jonghe, J. Phys. Chem. C, 2007, 111, 11003.

40 K. Toyoura, Y. Koyama, A. Kuwabara, F. Oba and I. Tanaka, Phys. Rev. B, 2008, 78, 214303.

41 J. Ding, J. Balachandran, X. Sang, W. Guo, J. S. Anchell, G. M. Veith, C. A. Bridges, Y. Cheng, C. M. Rouleau, J. D. Poplawsky, N. Bassiri-Gharb, R. R. Unocic and P. Ganesh, Chem. Mater, 2018, 30, 4919. 


\section{Table and Figure captions}

Table 1. The calculated potential barriers of proton rotation with various configurations of $Y$ dopants on $\mathrm{Zr}$ sites. Only the three configurations in the gray columns were calculated in Ref. [25].

Table 2. The calculated potential barriers of proton hopping with various configurations of $\mathrm{Y}$ dopants on Zr sites. Only the five configurations in the gray columns were calculated in Ref. [25].

Fig. 1. The calculated PES of a proton in the perfect $\mathrm{BaZrO}_{3}$ crystal [26]. Only the regions with a low potential energy below $0.3 \mathrm{eV}$ with reference to the most stable site are shown. The black spheres are the global energy minima corresponding to the most stable proton sites. The white and blue spheres are the rotation and hopping paths identified by the NEB method.

Fig. 2. (a) The employed supercell of $4 \times 4 \times 4$ unit cells for evaluating the potential barriers of proton migrations. (b)(c) The adjacent $\mathrm{Zr}$ sites around the proton rotation and hopping paths, which were taken into consideration for $\mathrm{Y}$ local configuration. Protons on sites $\mathrm{i}$ and $\mathrm{f}$ in the rotation path form an $\mathrm{OH}$ bond with the same $\mathrm{O}$ ion between $\mathrm{R} 1$ and $\mathrm{R} 2$. The site $\mathrm{i}$ is located on the plane through "R1, R2, R3, and R4", while the site $\mathrm{f}$ is on the plane through "R1, R2, R5, and R6". In the hopping path, sites $\mathrm{i}$ and $\mathrm{f}$ are located on the same plane as $\mathrm{H} 1, \mathrm{H} 2, \mathrm{H} 3$, and $\mathrm{H} 4$, forming an $\mathrm{OH}$ bond with the different $\mathrm{O}$ ions between "H1 and H2" and "H1 and H3", respectively.

Fig. 3. The differences in potential barrier between the forward and backward migrations $\left(\Delta E_{\mathrm{i}^{\prime} \rightarrow \mathrm{f}^{\prime}}^{\mathrm{mig}}-\Delta E_{\mathrm{f}^{\prime} \rightarrow \mathrm{i}^{\prime}}^{\mathrm{mig}}\right)$ only for the paths having inequivalent initial and final states. The initial state $i$ ' (or final state $f^{\prime}$ ) is here redefined as the state surrounded by more (or less) Y dopants.

Fig. 4. The local structures around proton sites in the initial and final states (i' and f') of path H2-1.

Fig. 5. The calculated potential barriers of all paths in Tables 1 and 2 classified into the eight paths in Ref. [25]. The paths H1-2 and H2-1 have two $\Delta E^{\text {mig }}$ for the forward and backward migrations.

Fig. 6. The estimated proton diffusivities as a function of inverse temperature by the KMC simulations in the range of $0 \leq x_{\mathrm{Y}} \leq 0.3$. A part of $\mathrm{Zr}$ sites were randomly substituted by (a) single $\mathrm{Y}$ 
ions and (b) Y-Y pairs, corresponding to the random and adjacent configurations, respectively. The black broken line in each figure is the reported proton diffusivity in $\mathrm{BaZr}_{0.8} \mathrm{Y}_{0.2} \mathrm{O}_{3-\delta}$, measured by the impedance spectroscopy [18].

Fig. 7. The estimated proton conductivities at 600 and $1000 \mathrm{~K}$ as a function of $\mathrm{Y}$ concentration. The blue and red lines correspond to the ideal and actual cases, where the hydration degree is equal to 1 and depends on the temperature due to the dehydration at high temperatures, respectively. In the actual case, the proton concentrations were estimated from the experimental hydration degree measured by the Karl Fischer titration method in the literature [16]. The solid and open circles correspond to the random and adjacent configuration of Y dopants, respectively.

Fig. 8. (a) Proton sites connecting to two rotation paths and two hopping paths, which are classified into 84 proton sites in total. These proton sites are numbered in the ascending order of the total number of Y dopants around the four paths. See Table S1 in the ESI for the detailed classification. (b)(c) The fraction of each type of proton sites in the KMC simulation cells $r_{\text {site }}$ (blue bars) and the existence probabilities of a proton at each site $p_{\mathrm{H}}{ }^{+}$(red bars) during the $\mathrm{KMC}$ simulations at $600 \mathrm{~K}$ in the random and adjacent configurations of $\mathrm{Y}$ dopants.

Fig. 9. (a)-(c) The local configurations of $Y$ ions around sites 60, 61, and 63. (d) The common $Y$ configuration in the sites 60,61 , and 63 , i.e., the Y-Y-Y triplet in the triangular configuration. The calculated potential barriers of the migration paths connecting to the two proton sites are also shown in the figure. 
Table 1. The calculated potential barriers of proton rotation with various configurations of $Y$ dopants on $\mathrm{Zr}$ sites. Only the three configurations in the gray columns were calculated in Ref. [25].

\begin{tabular}{|c|c|c|c|c|c|c|c|c|c|}
\hline \multirow[b]{2}{*}{$\#$ of Y } & \multirow[b]{2}{*}{ Path ID } & \multicolumn{6}{|c|}{$\mathrm{Zr}$ and $\mathrm{Y}$ configuration in B sites } & \multirow{2}{*}{$\Delta E_{\mathrm{i} \rightarrow \mathrm{f}}^{\mathrm{mig}} / \mathrm{eV}$} & \multirow{2}{*}{$\Delta E_{\mathrm{f} \rightarrow \mathrm{i}}^{\mathrm{mig}} / \mathrm{eV}$} \\
\hline & & $\mathrm{R} 1$ & $\mathrm{R} 2$ & R3 & $\mathrm{R} 4$ & R5 & R6 & & \\
\hline 0 & R0-1 & $\mathrm{Zr}$ & $\mathrm{Zr}$ & $\mathrm{Zr}$ & $\mathrm{Zr}$ & $\mathrm{Zr}$ & $\mathrm{Zr}$ & 0.17 & 0.17 \\
\hline \multirow{2}{*}{1} & R1-1 & $\mathrm{Y}$ & $\mathrm{Zr}$ & $\mathrm{Zr}$ & $\mathrm{Zr}$ & $\mathrm{Zr}$ & $\mathrm{Zr}$ & 0.18 & 0.18 \\
\hline & $\mathrm{R} 1-2$ & $\mathrm{Zr}$ & $\mathrm{Zr}$ & $\mathrm{Zr}$ & $\mathrm{Zr}$ & $\mathrm{Y}$ & $\mathrm{Zr}$ & 0.11 & 0.25 \\
\hline \multirow{6}{*}{2} & R2-1 & $\mathrm{Y}$ & $\mathrm{Y}$ & $\mathrm{Zr}$ & $\mathrm{Zr}$ & $\mathrm{Zr}$ & $\mathrm{Zr}$ & 0.25 & 0.25 \\
\hline & $\mathrm{R} 2-2$ & $\mathrm{Zr}$ & $\mathrm{Zr}$ & $\mathrm{Zr}$ & $\mathrm{Zr}$ & $\mathrm{Y}$ & $\mathrm{Y}$ & 0.09 & 0.31 \\
\hline & $\mathrm{R} 2-3$ & $\mathrm{Zr}$ & $\mathrm{Zr}$ & $\mathrm{Y}$ & $\mathrm{Zr}$ & Y & $\mathrm{Zr}$ & 0.20 & 0.20 \\
\hline & $\mathrm{R} 2-4$ & $\mathrm{Zr}$ & $\mathrm{Zr}$ & $\mathrm{Zr}$ & $\mathrm{Y}$ & Y & $\mathrm{Zr}$ & 0.17 & 0.17 \\
\hline & $\mathrm{R} 2-5$ & $\mathrm{Y}$ & $\mathrm{Zr}$ & $\mathrm{Zr}$ & $\mathrm{Zr}$ & $\mathrm{Y}$ & $\mathrm{Zr}$ & 0.08 & 0.29 \\
\hline & R2-6 & $\mathrm{Y}$ & $\mathrm{Zr}$ & $\mathrm{Zr}$ & $\mathrm{Zr}$ & $\mathrm{Zr}$ & $\mathrm{Y}$ & 0.11 & 0.22 \\
\hline \multirow{6}{*}{3} & R3-1 & $\mathrm{Zr}$ & $\mathrm{Zr}$ & $\mathrm{Y}$ & $\mathrm{Zr}$ & $\mathrm{Y}$ & $\mathrm{Y}$ & 0.20 & 0.32 \\
\hline & R3-2 & $\mathrm{Y}$ & $\mathrm{Zr}$ & $\mathrm{Y}$ & $\mathrm{Zr}$ & $\mathrm{Y}$ & $\mathrm{Zr}$ & 0.20 & 0.20 \\
\hline & R3-3 & Y & $\mathrm{Zr}$ & $\mathrm{Zr}$ & $\mathrm{Y}$ & $\mathrm{Zr}$ & $\mathrm{Y}$ & 0.20 & 0.20 \\
\hline & R3-4 & $\mathrm{Y}$ & $\mathrm{Zr}$ & $\mathrm{Zr}$ & $\mathrm{Zr}$ & $\mathrm{Y}$ & $\mathrm{Y}$ & 0.24 & 0.49 \\
\hline & R3-5 & $\mathrm{Y}$ & $\mathrm{Zr}$ & $\mathrm{Zr}$ & $\mathrm{Y}$ & $\mathrm{Y}$ & $\mathrm{Zr}$ & 0.08 & 0.37 \\
\hline & R3-6 & $\mathrm{Y}$ & $\mathrm{Y}$ & $\mathrm{Zr}$ & $\mathrm{Zr}$ & $\mathrm{Y}$ & $\mathrm{Zr}$ & 0.13 & 0.33 \\
\hline \multirow{6}{*}{4} & R4-1 & $\mathrm{Zr}$ & $\mathrm{Zr}$ & $\mathrm{Y}$ & $\mathrm{Y}$ & $\mathrm{Y}$ & $\mathrm{Y}$ & 0.17 & 0.17 \\
\hline & R4-2 & Y & $\mathrm{Y}$ & $\mathrm{Y}$ & $\mathrm{Y}$ & $\mathrm{Zr}$ & $\mathrm{Zr}$ & 0.21 & 0.11 \\
\hline & R4-3 & $\mathrm{Y}$ & $\mathrm{Y}$ & $\mathrm{Zr}$ & $\mathrm{Y}$ & $\mathrm{Zr}$ & $\mathrm{Y}$ & 0.40 & 0.40 \\
\hline & R4-4 & $\mathrm{Y}$ & $\mathrm{Y}$ & $\mathrm{Y}$ & $\mathrm{Zr}$ & $\mathrm{Zr}$ & $\mathrm{Y}$ & 0.30 & 0.30 \\
\hline & R4-5 & $\mathrm{Zr}$ & $\mathrm{Y}$ & $\mathrm{Y}$ & $\mathrm{Y}$ & $\mathrm{Zr}$ & $\mathrm{Y}$ & 0.48 & 0.34 \\
\hline & R4-6 & $\mathrm{Zr}$ & $\mathrm{Y}$ & $\mathrm{Y}$ & $\mathrm{Y}$ & $\mathrm{Y}$ & $\mathrm{Zr}$ & 0.45 & 0.22 \\
\hline \multirow{2}{*}{5} & R5-1 & $\mathrm{Zr}$ & $\mathrm{Y}$ & $\mathrm{Y}$ & $\mathrm{Y}$ & $\mathrm{Y}$ & $\mathrm{Y}$ & 0.17 & 0.17 \\
\hline & R5-2 & $\mathrm{Y}$ & $\mathrm{Y}$ & $\mathrm{Y}$ & $\mathrm{Y}$ & $\mathrm{Zr}$ & $\mathrm{Y}$ & 0.54 & 0.34 \\
\hline 6 & R6-1 & $\mathrm{Y}$ & $\mathrm{Y}$ & $\mathrm{Y}$ & $\mathrm{Y}$ & $\mathrm{Y}$ & $\mathrm{Y}$ & 1.08 & 1.08 \\
\hline
\end{tabular}


Table 2. The calculated potential barriers of proton hopping with various configurations of $Y$ dopants on $\mathrm{Zr}$ sites. Only the five configurations in the gray columns were calculated in Ref. [25].

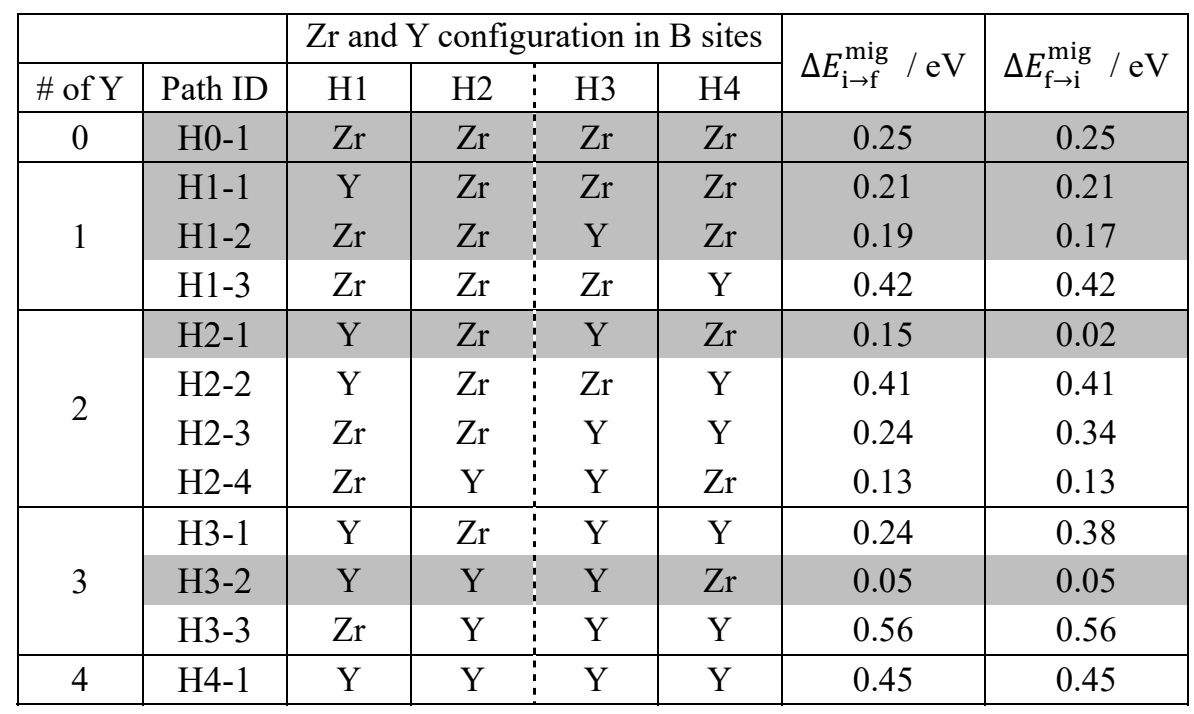




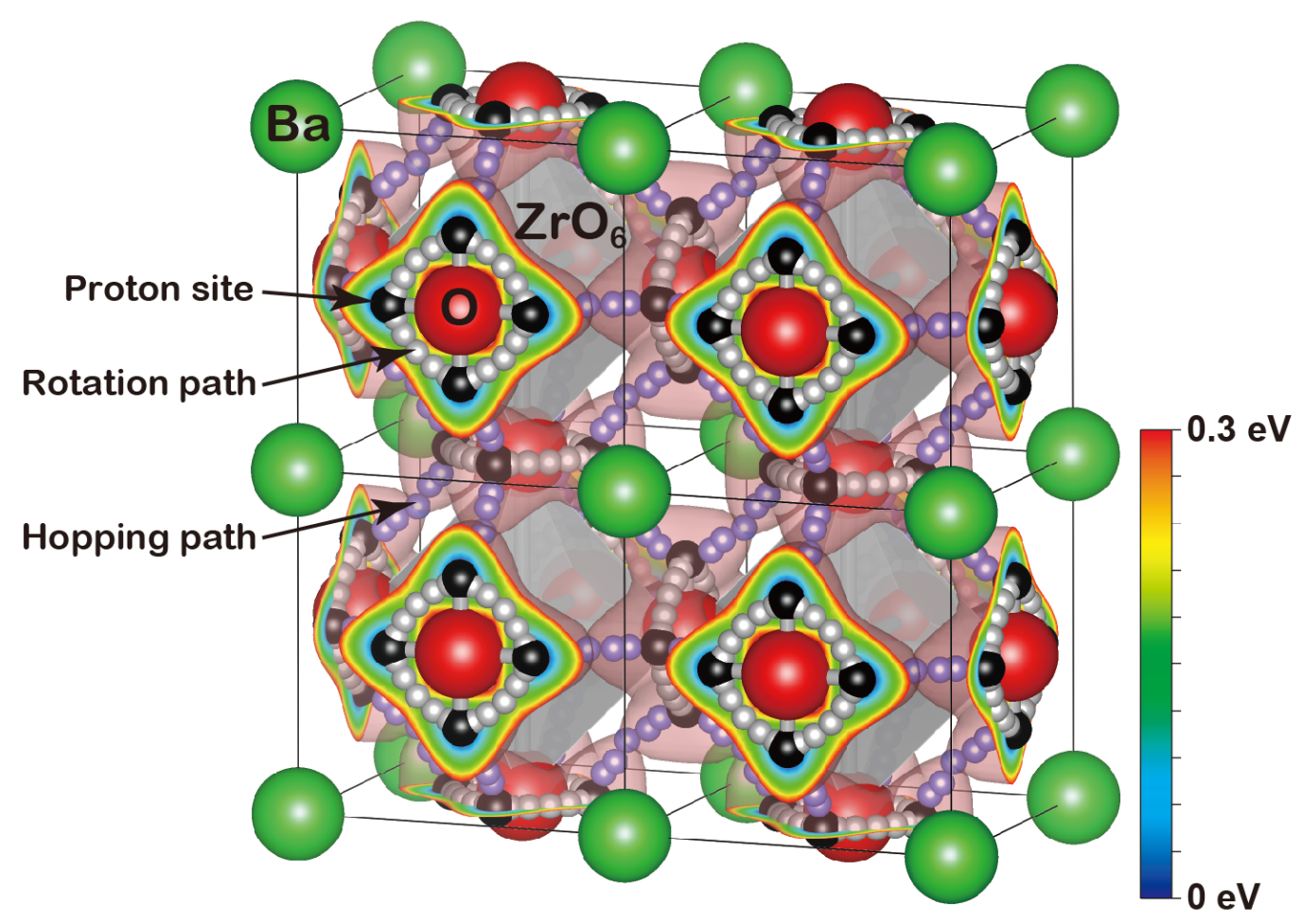

Fig. 1. The calculated PES of a proton in the perfect $\mathrm{BaZrO}_{3}$ crystal [26]. Only the regions with a low potential energy below $0.3 \mathrm{eV}$ with reference to the most stable site are shown. The black spheres are the global energy minima corresponding to the most stable proton sites. The white and blue spheres are the rotation and hopping paths identified by the NEB method. 


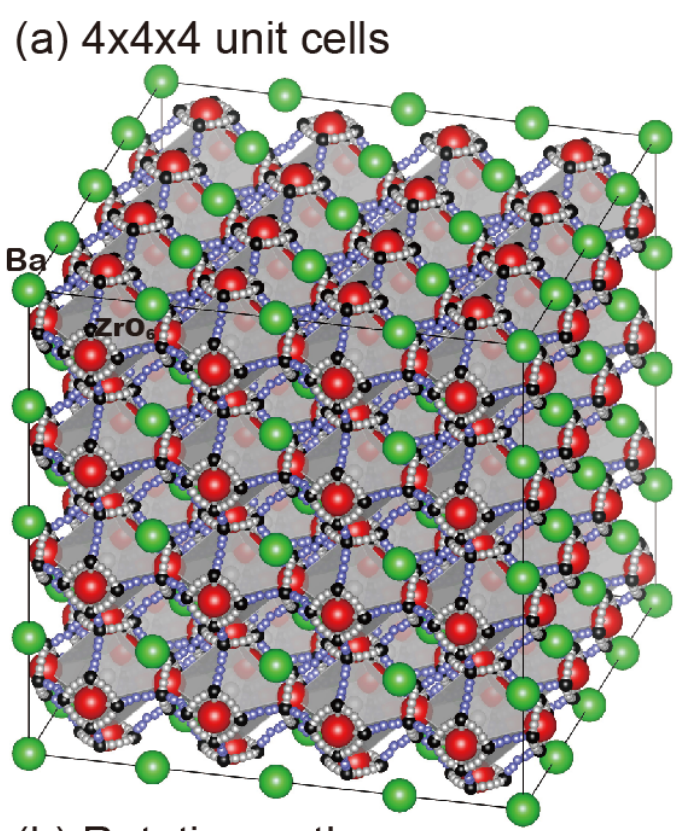

(b) Rotation path

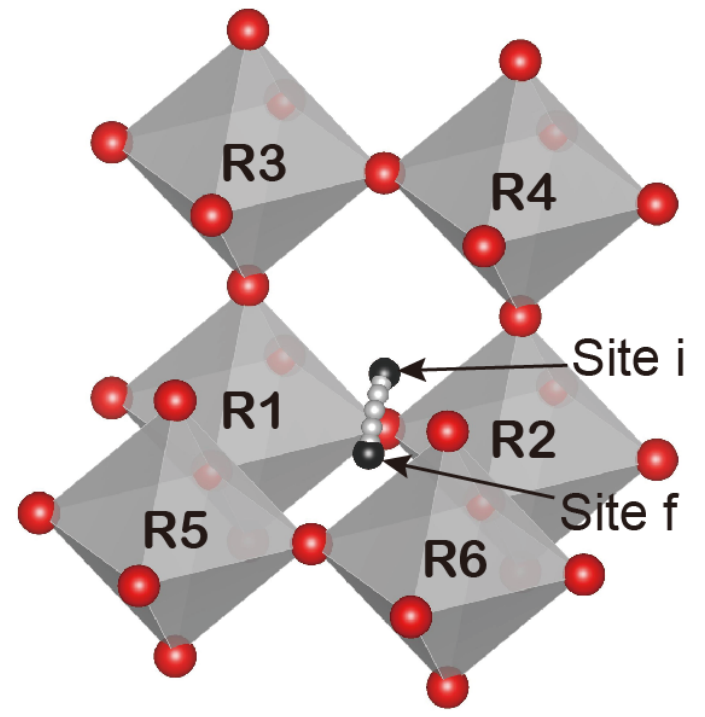

(c) Hopping path

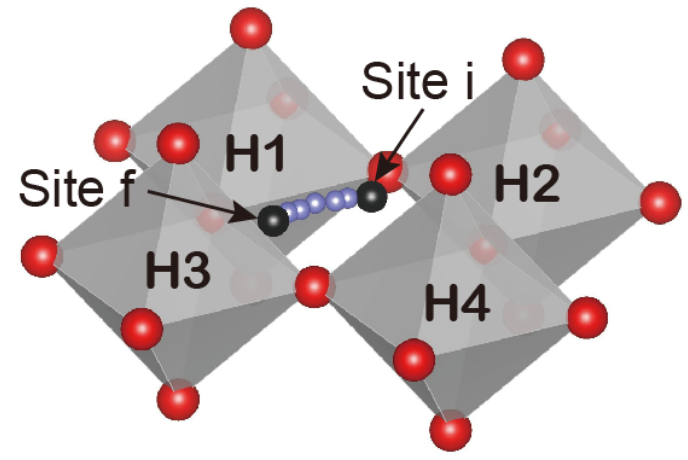

Fig. 2. (a) The employed supercell of $4 \times 4 \times 4$ unit cells for evaluating the potential barriers of proton migrations. (b)(c) The adjacent $\mathrm{Zr}$ sites around the proton rotation and hopping paths, which were taken into consideration for $\mathrm{Y}$ local configuration. Protons on sites $\mathrm{i}$ and $\mathrm{f}$ in the rotation path form an $\mathrm{OH}$ bond with the same $\mathrm{O}$ ion between $\mathrm{R} 1$ and $\mathrm{R} 2$. The site $\mathrm{i}$ is located on the plane through "R1, $\mathrm{R} 2$, R3, and R4", while the site $\mathrm{f}$ is on the plane through "R1, R2, R5, and R6". In the hopping path, sites $\mathrm{i}$ and $\mathrm{f}$ are located on the same plane as $\mathrm{H} 1, \mathrm{H} 2, \mathrm{H} 3$, and $\mathrm{H} 4$, forming an $\mathrm{OH}$ bond with the different $\mathrm{O}$ ions between "H1 and $\mathrm{H} 2$ " and "H1 and H3", respectively. 


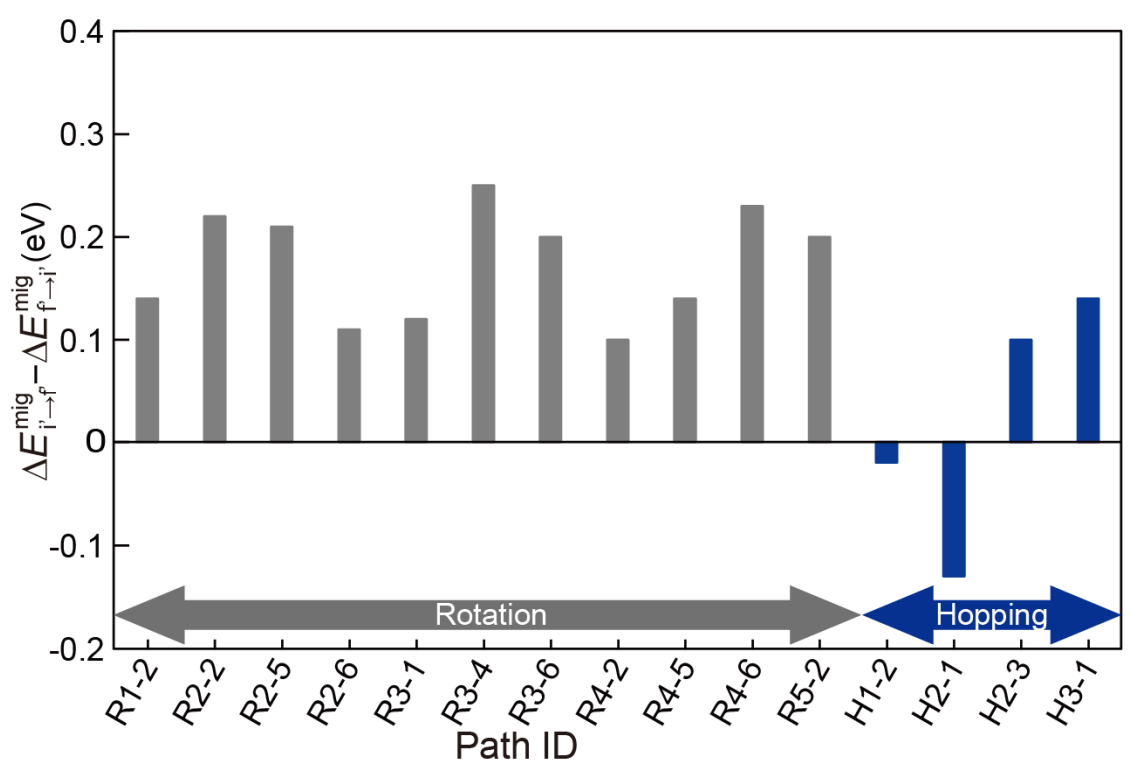

Fig. 3. The differences in potential barrier between the forward and backward migrations $\left(\Delta E_{\mathrm{i}^{\prime} \rightarrow \mathrm{f}^{\prime}}^{\mathrm{mig}}-\Delta E_{\mathrm{f}^{\prime} \rightarrow \mathrm{i}^{\prime}}^{\mathrm{mig}}\right)$ only for the paths having inequivalent initial and final states. The initial state $i$ ' (or final state $f^{\prime}$ ) is here redefined as the state surrounded by more (or less) Y dopants. 


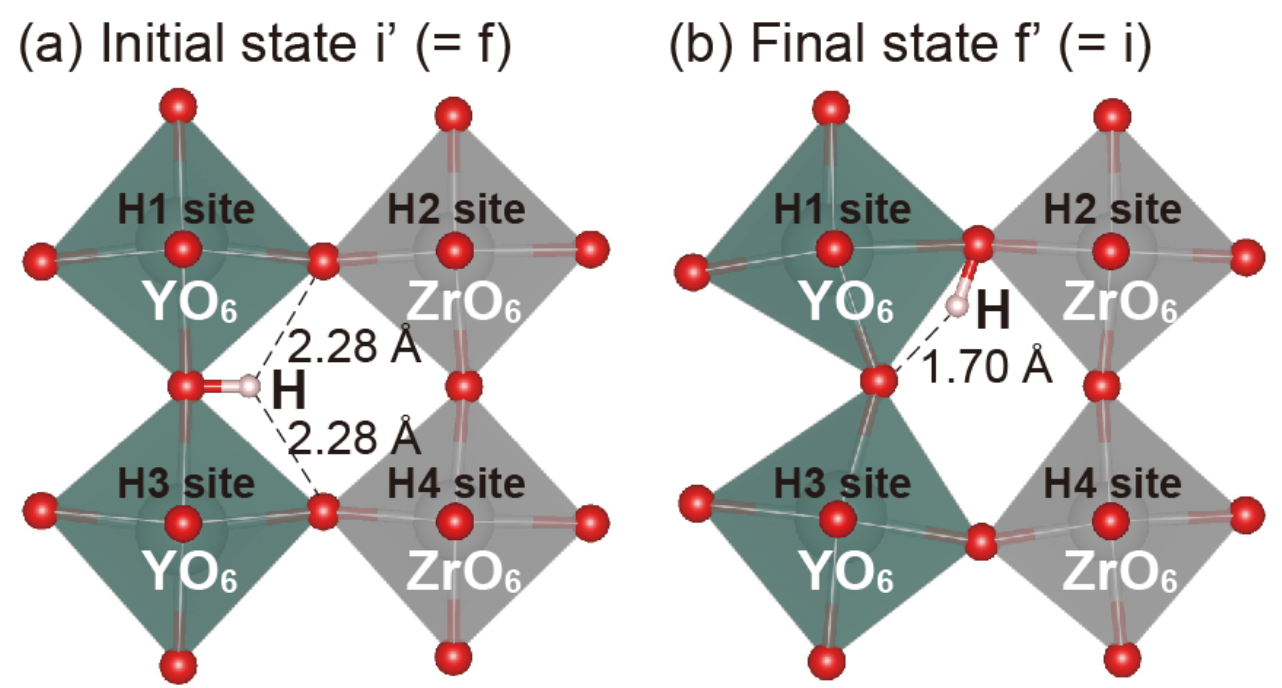

Fig. 4. The local structures around proton sites in the initial and final states (i' and f') of path H2-1. 


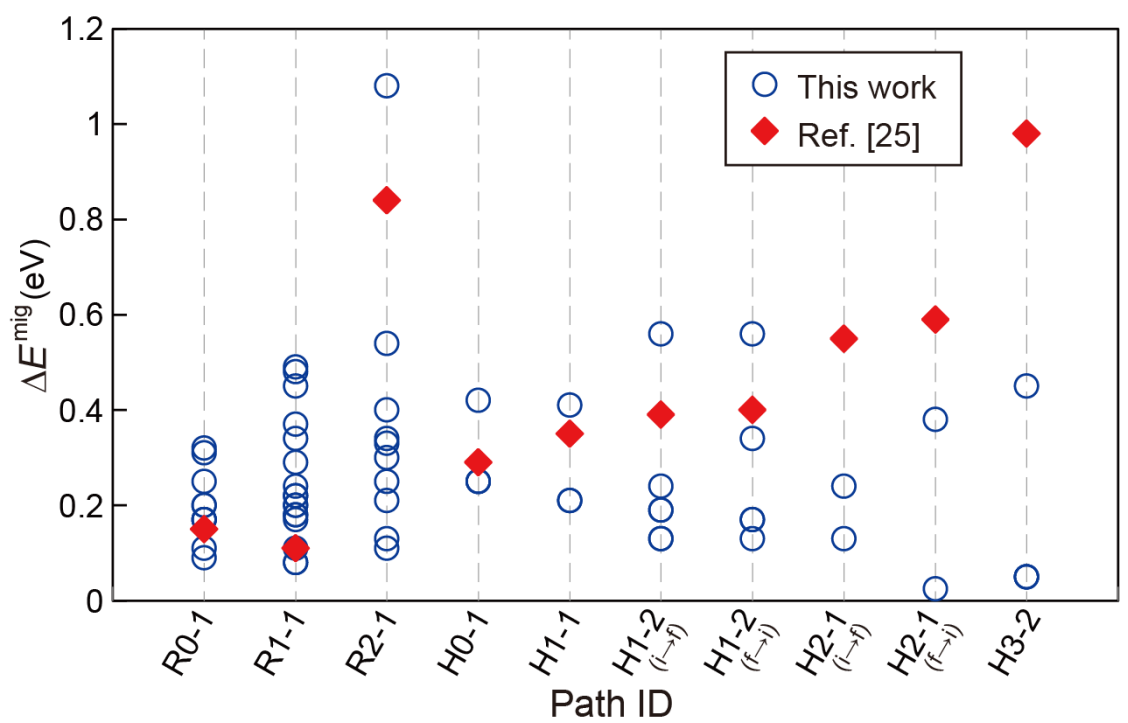

Fig. 5. The calculated potential barriers of all paths in Tables 1 and 2 classified into the eight paths in Ref. [25]. The paths H1-2 and H2-1 have two $\Delta E^{\mathrm{mig}}$ for the forward and backward migrations. 


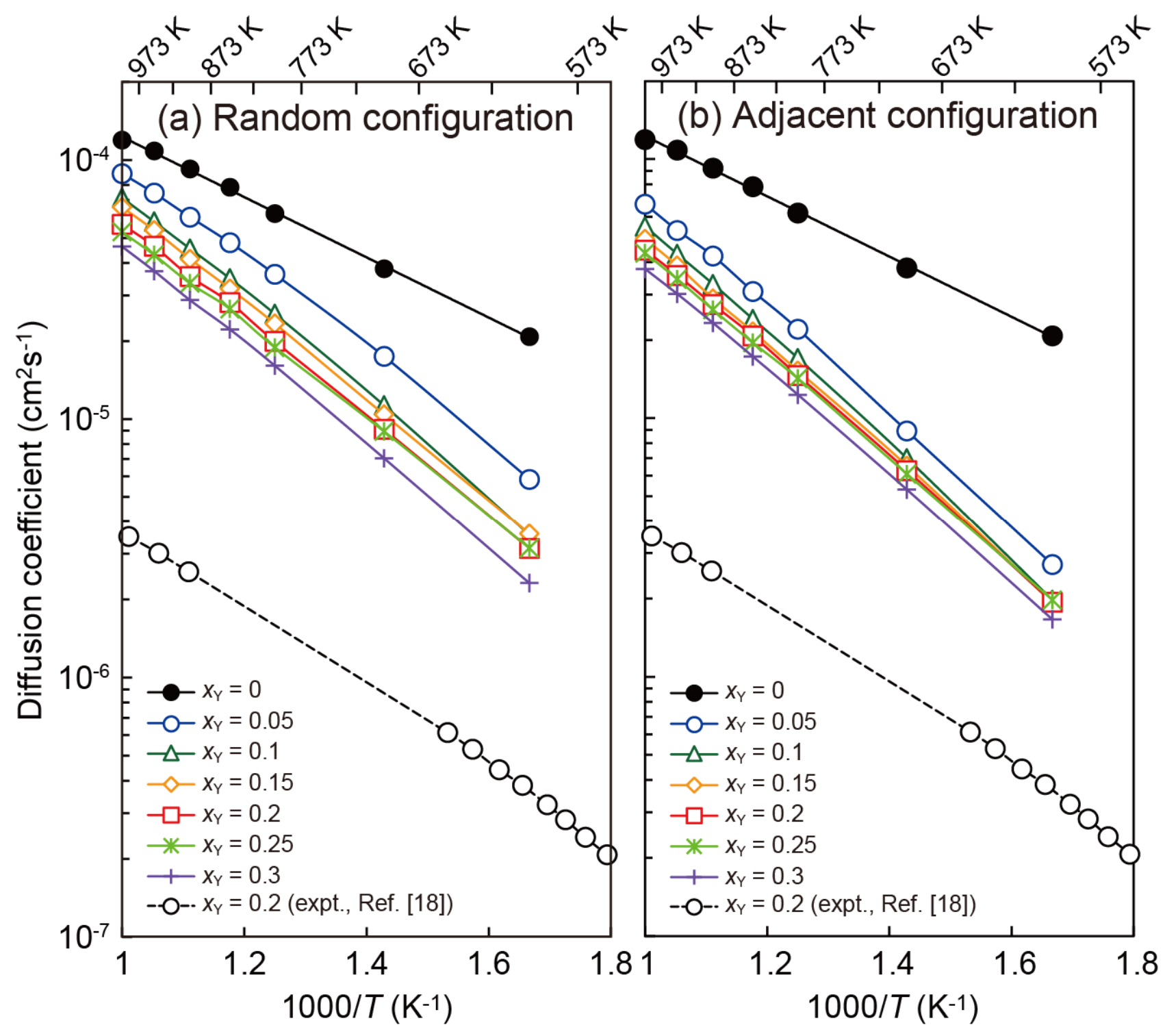

Fig. 6. The estimated proton diffusivities as a function of inverse temperature by the KMC simulations in the range of $0 \leq x_{\mathrm{Y}} \leq 0.3$. A part of $\mathrm{Zr}$ sites were randomly substituted by (a) single $\mathrm{Y}$ ions and (b) Y-Y pairs, corresponding to the random and adjacent configurations, respectively. The black broken line in each figure is the reported proton diffusivity in $\mathrm{BaZr}_{0.8} \mathrm{Y}_{0.2} \mathrm{O}_{3-\delta}$, measured by the impedance spectroscopy [18]. 

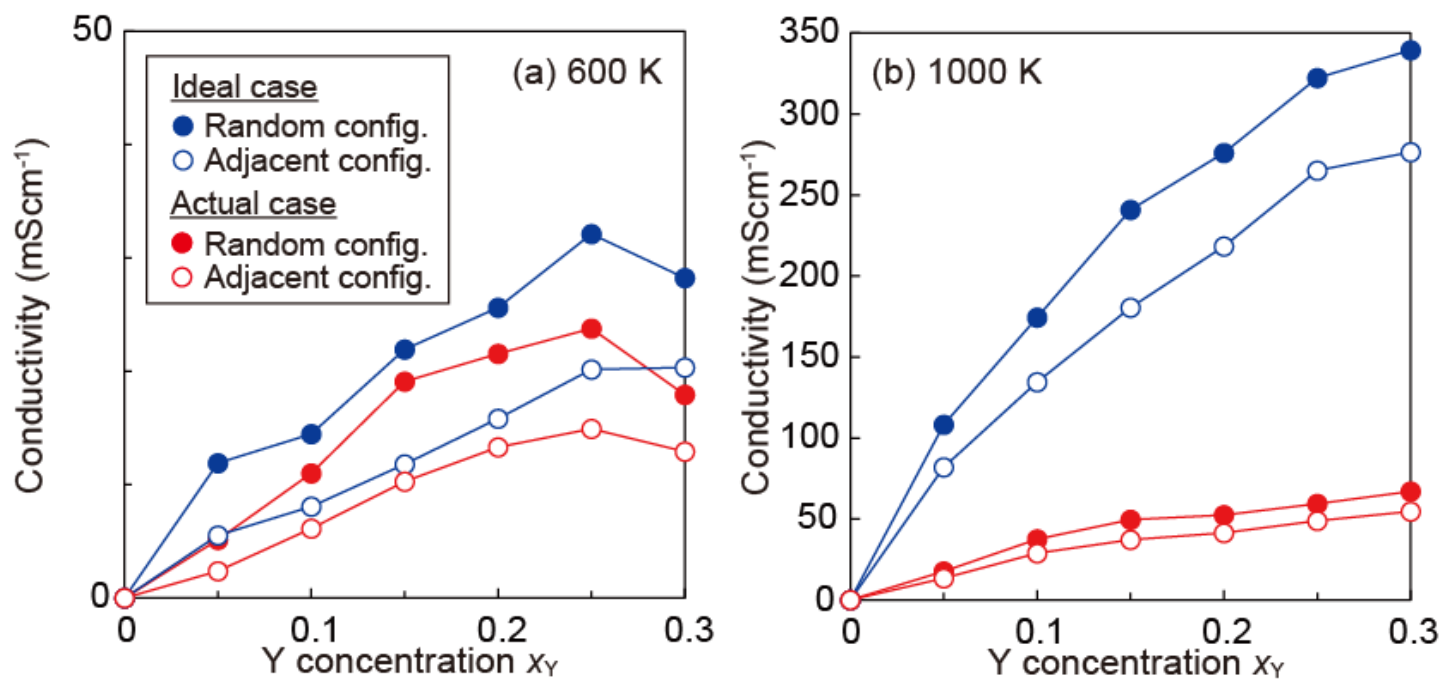

Fig. 7. The estimated proton conductivities at 600 and $1000 \mathrm{~K}$ as a function of $\mathrm{Y}$ concentration. The blue and red lines correspond to the ideal and actual cases, where the hydration degree is equal to 1 and depends on the temperature due to the dehydration at high temperatures, respectively. In the actual case, the proton concentrations were estimated from the experimental hydration degree measured by the Karl Fischer titration method in the literature [16]. The solid and open circles correspond to the random and adjacent configuration of Y dopants, respectively. 
(a) Proton site

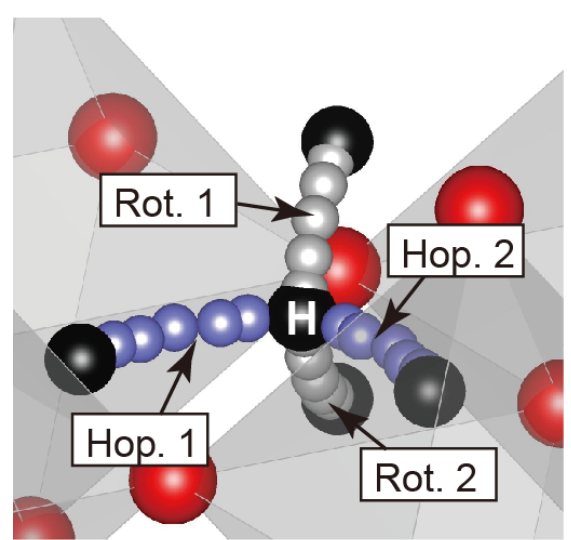

(b) Random configuration

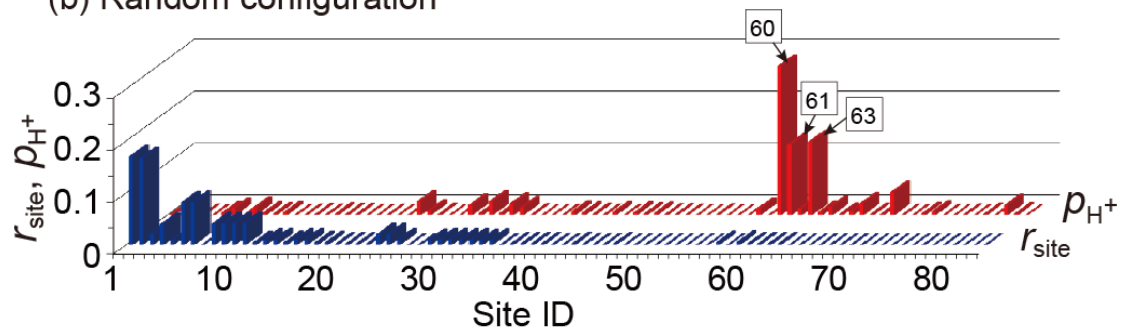

(c) Adjacent configuration

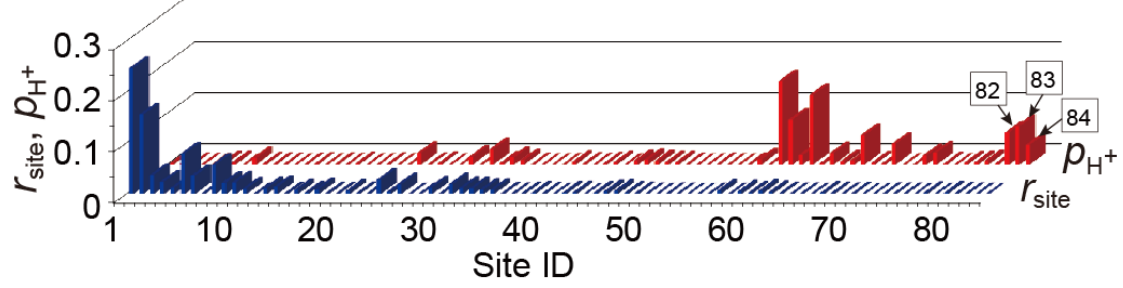

Fig. 8. (a) Proton sites connecting to two rotation paths and two hopping paths, which are classified into 84 proton sites in total. These proton sites are numbered in the ascending order of the total number of Y dopants around the four paths. See Table S1 in the ESI for the detailed classification. (b)(c) The fraction of each type of proton sites in the KMC simulation cells $r_{\text {site }}$ (blue bars) and the existence probabilities of a proton at each site $\mathrm{pH}^{+}$(red bars) during the $\mathrm{KMC}$ simulations at $600 \mathrm{~K}$ in the random and adjacent configurations of Y dopants. 
(a) Site 60

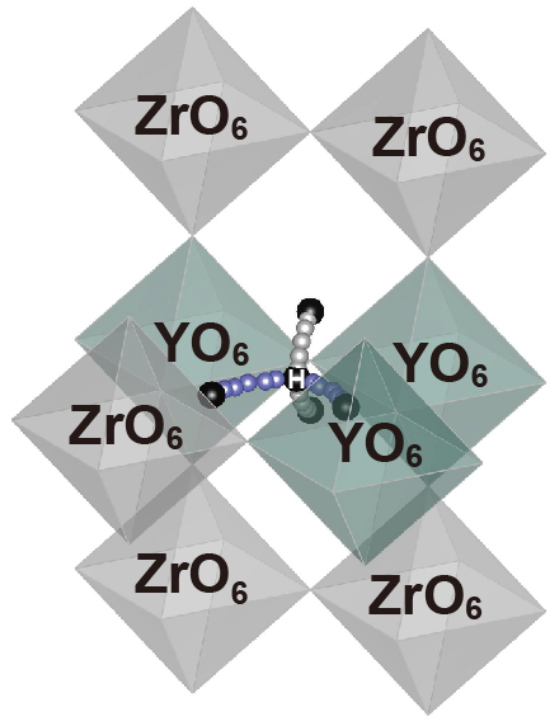

(c) Site 63

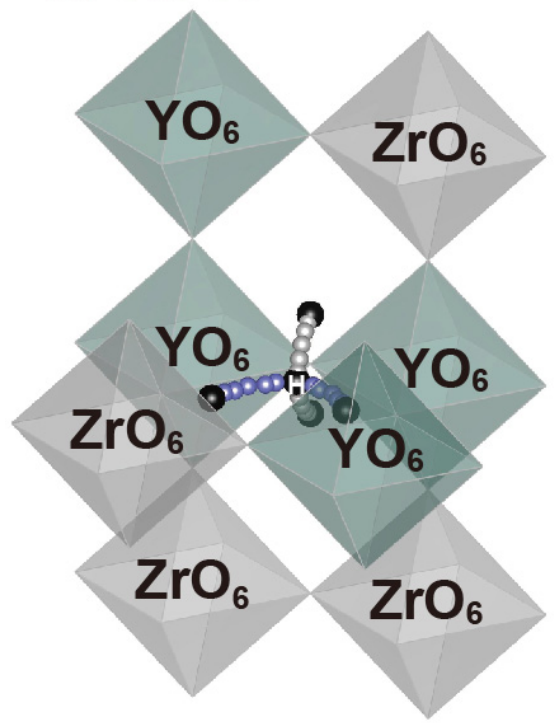

(b) Site 61

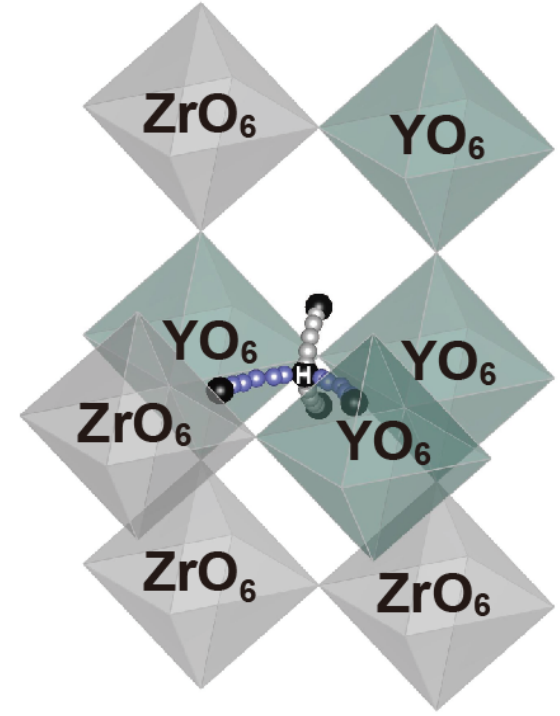

(d) Triangular $Y$ configuration

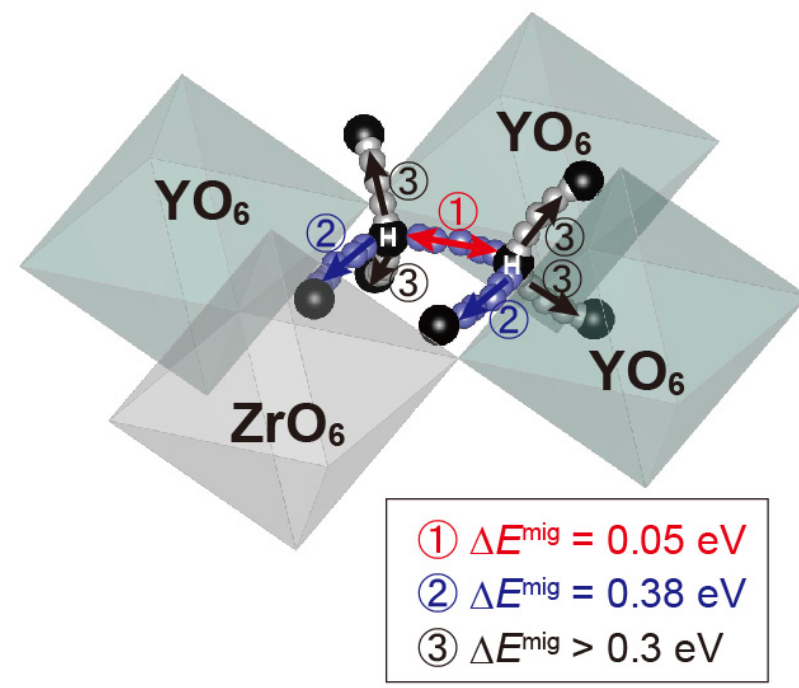

Fig. 9. (a)-(c) The local configurations of $Y$ ions around sites 60, 61, and 63. (d) The common $Y$ configuration in the sites 60,61 , and 63 , i.e., the Y-Y-Y triplet in the triangular configuration. The calculated potential barriers of the migration paths connecting to the two proton sites are also shown in the figure. 


\section{Supplementary Information}

\section{Preferential Proton Conduction along Three-Dimensional Dopant Network} in Yttrium-Doped Barium Zirconate: A First-Principles Study

Kazuaki Toyoura,* Weijie Meng, Donglin Han, and Tetsuya Uda

Department of Materials Science and Engineering, Kyoto University, Yoshida, Sakyo, Kyoto 606-8501, Japan.
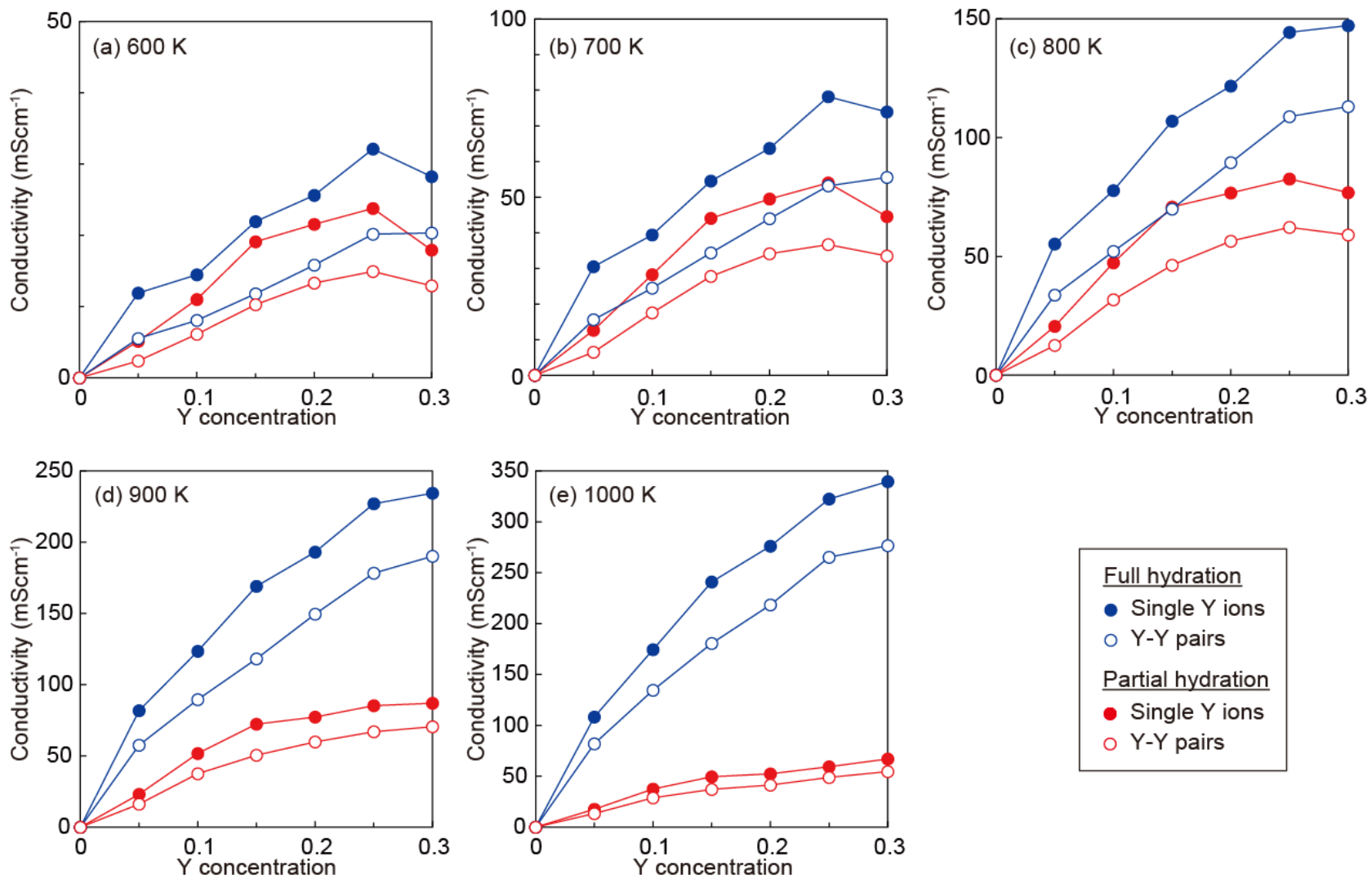

Full hydration

- Single $Y$ ions

○ Y-Y pairs

Partial hydration

- Single $Y$ ions

○ Y-Y pairs

Fig. S1. The estimated proton conductivities in the range of 600 and $1000 \mathrm{~K}$ as a function of $\mathrm{Y}$ concentration. The blue and red lines correspond to the fully and partially hydrated crystals, respectively. In the partially-hydrated situation, the proton concentrations were estimated from the actual proton concentrations measured by the Karl Fischer titration method in the literature [16]. The solid and open circles correspond to the random and adjacent configuration of $\mathrm{Y}$ dopants, respectively. 

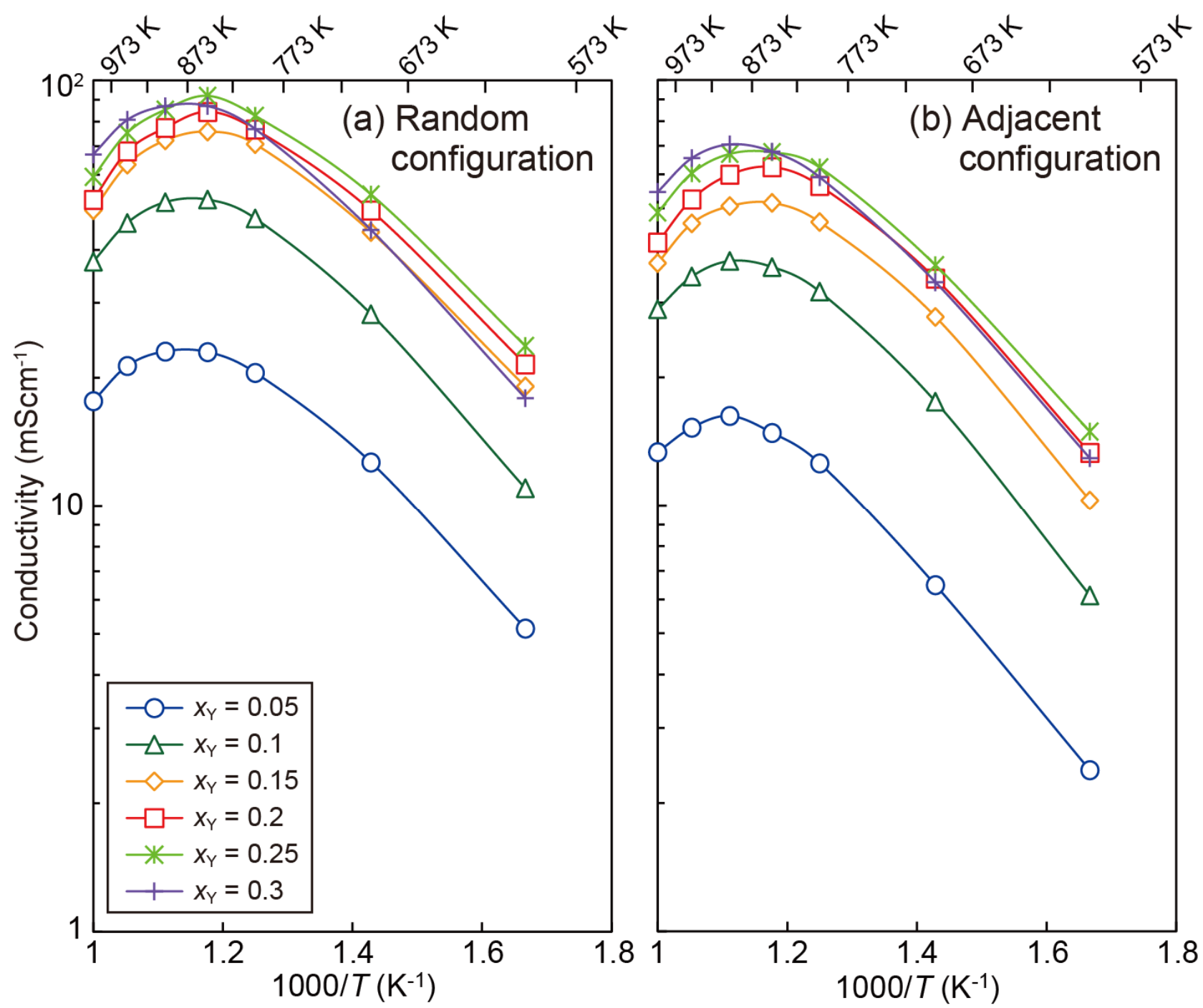

Fig. S2. The estimated proton conductivities as a function of inverse temperature in the range of $0 \leq$ $X Y \leq 0.3$ with the (a) random and (b) adjacent configurations of $\mathrm{Y}$ dopants. The proton concentrations were estimated from the actual proton concentrations measured by the Karl Fischer titration method in the literature [16]. 
Table S1. All proton sites in Y-doped $\mathrm{BaZrO}_{3}$ classified by the types of proton rotation and hopping paths from the individual proton site. "a" and " $b$ " in path ID mean the forward and backward migrations, respectively. \#Y is the total number of $\mathrm{Y}$ dopants around the four paths.

\begin{tabular}{|c|c|c|c|c|c|c|c|c|c|c|c|}
\hline & & & $\mathrm{Pat}$ & ID & & & & & Patl & & \\
\hline Site & $\# \mathrm{Y}$ & Rot & tion & Hop & jing & Site & $\# Y$ & Rot & ion & $\mathrm{Hor}$ & ping \\
\hline 1 & 0 & R0-1a & R0-1a & H0-1a & H0-1a & 43 & 10 & $\mathrm{R} 2-2 \mathrm{~b}$ & R4-1a & $\mathrm{H} 2-3 \mathrm{a}$ & $\mathrm{H} 2-3 \mathrm{a}$ \\
\hline 2 & 1 & $\mathrm{R} 1-2 \mathrm{a}$ & R0-1a & $\mathrm{H} 0-1 \mathrm{a}$ & $\mathrm{H} 0-1 \mathrm{a}$ & 44 & 10 & R3-6a & R3-6a & $\mathrm{H} 2-1 \mathrm{~b}$ & $\mathrm{H} 2-1 \mathrm{~b}$ \\
\hline 3 & 2 & R0-1a & R2-2a & H0-1a & $\mathrm{H} 0-1 \mathrm{a}$ & 45 & 10 & R3-3a & R3-3a & $\mathrm{H} 2-2 \mathrm{a}$ & $\mathrm{H} 2-4 \mathrm{a}$ \\
\hline 4 & 2 & R1-2a & R1-2a & H0-1a & H0-1a & 46 & 10 & R3-2a & R3-2a & $\mathrm{H} 2-1 \mathrm{a}$ & $\mathrm{H} 2-3 \mathrm{~b}$ \\
\hline 5 & 3 & R1-2a & R2-2a & H0-1a & H0-1a & 47 & 10 & R2-1a & R4-2b & $\mathrm{H} 2-1 \mathrm{~b}$ & $\mathrm{H} 2-1 \mathrm{~b}$ \\
\hline 6 & 4 & $\mathrm{R} 1-2 \mathrm{~b}$ & $\mathrm{R} 1-2 \mathrm{~b}$ & H1-2a & H1-3a & 48 & 10 & $R 2-5 b$ & $\mathrm{R} 4-5 \mathrm{~b}$ & H2-1a & $\mathrm{H} 2-3 \mathrm{~b}$ \\
\hline 7 & 4 & R1-1a & R1-1a & H1-1a & $\mathrm{H} 1-2 \mathrm{~b}$ & 49 & 11 & R3-6a & R4-2b & $\mathrm{H} 2-1 \mathrm{~b}$ & $\mathrm{H} 2-1 \mathrm{~b}$ \\
\hline 8 & 4 & R2-2a & R2-2a & H0-1a & H0-1a & 50 & 11 & R3-2a & $\mathrm{R} 4-5 \mathrm{~b}$ & $\mathrm{H} 2-1 \mathrm{a}$ & $\mathrm{H} 2-3 \mathrm{~b}$ \\
\hline 9 & 5 & R1-1a & R2-5a & H1-1a & $\mathrm{H} 1-2 \mathrm{~b}$ & 51 & 11 & R3-5b & $\mathrm{R} 4-5 \mathrm{~b}$ & H2-1a & $\mathrm{H} 2-3 \mathrm{~b}$ \\
\hline 10 & 5 & $\mathrm{R} 1-2 \mathrm{~b}$ & R2-4a & H1-2a & H1-3a & 52 & 11 & R3-3a & R4-6b & $\mathrm{H} 2-2 \mathrm{a}$ & $\mathrm{H} 2-4 \mathrm{a}$ \\
\hline 11 & 5 & R1-2b & R2-3a & H1-2a & $\mathrm{H} 1-3 \mathrm{a}$ & 53 & 11 & R3-5a & $\mathrm{R} 4-6 \mathrm{~b}$ & $\mathrm{H} 2-2 \mathrm{a}$ & $\mathrm{H} 2-4 \mathrm{a}$ \\
\hline 12 & 5 & R1-1a & R2-6a & H1-1a & H1-2b & 54 & 11 & R4-1a & R3-1b & $\mathrm{H} 2-3 \mathrm{a}$ & $\mathrm{H} 2-3 \mathrm{a}$ \\
\hline 13 & 6 & R2-6a & R2-6a & H1-1a & $\mathrm{H} 1-2 \mathrm{~b}$ & 55 & 12 & R4-1a & R4-1a & H2-3a & $\mathrm{H} 2-3 \mathrm{a}$ \\
\hline 14 & 6 & $\mathrm{R} 1-2 \mathrm{~b}$ & R3-1a & H1-2a & H1-3a & 56 & 12 & $\mathrm{R} 4-6 \mathrm{~b}$ & R4-6b & $\mathrm{H} 2-2 \mathrm{a}$ & $\mathrm{H} 2-4 \mathrm{a}$ \\
\hline 15 & 6 & R1-1a & R3-4a & H1-1a & $\mathrm{H} 1-2 \mathrm{~b}$ & 57 & 12 & R4-2b & $\mathrm{R} 4-2 \mathrm{~b}$ & $\mathrm{H} 2-1 \mathrm{~b}$ & $\mathrm{H} 2-1 \mathrm{~b}$ \\
\hline 16 & 6 & R2-4a & R2-4a & H1-2a & H1-3a & 58 & 12 & R3-4b & R3-4b & H3-1a & $\mathrm{H} 3-3 \mathrm{a}$ \\
\hline 17 & 6 & $\mathrm{R} 2-5 \mathrm{a}$ & R2-6a & H1-1a & $\mathrm{H} 1-2 \mathrm{~b}$ & 59 & 12 & $R 4-5 b$ & $\mathrm{R} 4-5 \mathrm{~b}$ & $\mathrm{H} 2-1 \mathrm{a}$ & $\mathrm{H} 2-3 \mathrm{~b}$ \\
\hline 18 & 6 & R2-3a & R2-4a & H1-2a & H1-3a & 60 & 12 & R3-6b & R3-6b & H3-1b & H3-2a \\
\hline 19 & 6 & $R 2-5 a$ & $R 2-5 a$ & H1-1a & H1-2b & 61 & 13 & R3-6b & R4-3a & H3-1b & H3-2a \\
\hline 20 & 6 & R2-3a & R2-3a & H1-2a & H1-3a & 62 & 13 & R3-4b & R4-5a & H3-1a & $\mathrm{H} 3-3 \mathrm{a}$ \\
\hline 21 & 7 & $\mathrm{R} 2-3 \mathrm{a}$ & R3-1a & $\mathrm{H} 1-2 \mathrm{a}$ & $\mathrm{H} 1-3 \mathrm{a}$ & 63 & 13 & R4-4a & R3-6b & H3-1b & $\mathrm{H} 3-2 \mathrm{a}$ \\
\hline 22 & 7 & $\mathrm{R} 2-5 \mathrm{a}$ & R3-4a & H1-1a & $\mathrm{H} 1-2 \mathrm{~b}$ & 64 & 13 & R3-4b & R4-6a & H3-1a & $\mathrm{H} 3-3 \mathrm{a}$ \\
\hline 23 & 7 & R2-6a & R3-4a & H1-1a & H1-2b & 65 & 14 & R4-4a & R4-4a & H3-1b & H3-2a \\
\hline 24 & 7 & $\mathrm{R} 2-4 \mathrm{a}$ & R3-1a & H1-2a & H1-3a & 66 & 14 & R4-5a & R4-5a & H3-1a & H3-3a \\
\hline 25 & 8 & $R 2-5 b$ & $\mathrm{R} 2-5 \mathrm{~b}$ & $\mathrm{H} 2-1 \mathrm{a}$ & $\mathrm{H} 2-3 b$ & 67 & 14 & R4-3a & R4-3a & H3-1b & H3-2a \\
\hline 26 & 8 & R2-6b & R2-6b & $\mathrm{H} 2-2 \mathrm{a}$ & H2-4a & 68 & 14 & R3-6b & R5-2b & H3-1b & H3-2a \\
\hline 27 & 8 & R2-2b & R2-2b & $\mathrm{H} 2-3 \mathrm{a}$ & $\mathrm{H} 2-3 \mathrm{a}$ & 69 & 14 & R3-4b & R5-1a & H3-1a & $\mathrm{H} 3-3 \mathrm{a}$ \\
\hline 28 & 8 & R3-1a & R3-1a & $\mathrm{H} 1-2 \mathrm{a}$ & $\mathrm{H} 1-3 \mathrm{a}$ & 70 & 14 & R4-5a & R4-6a & H3-1a & $\mathrm{H} 3-3 \mathrm{a}$ \\
\hline 29 & 8 & R3-4a & R3-4a & H1-1a & $\mathrm{H} 1-2 \mathrm{~b}$ & 71 & 14 & R4-4a & R4-3a & H3-1b & H3-2a \\
\hline 30 & 8 & R2-1a & R2-1a & $\mathrm{H} 2-1 \mathrm{~b}$ & $\mathrm{H} 2-1 \mathrm{~b}$ & 72 & 14 & R4-6a & R4-6a & H3-1a & $\mathrm{H} 3-3 \mathrm{a}$ \\
\hline 31 & 9 & R2-6b & R3-3a & $\mathrm{H} 2-2 \mathrm{a}$ & $\mathrm{H} 2-4 \mathrm{a}$ & 73 & 15 & R4-6a & R5-1a & H3-1a & $\mathrm{H} 3-3 \mathrm{a}$ \\
\hline 32 & 9 & $R 2-5 b$ & R3-2a & $\mathrm{H} 2-1 \mathrm{a}$ & $\mathrm{H} 2-3 \mathrm{~b}$ & 74 & 15 & R4-3a & $\mathrm{R} 5-2 \mathrm{~b}$ & H3-1b & H3-2a \\
\hline 33 & 9 & $R 2-2 b$ & R3-1b & $\mathrm{H} 2-3 \mathrm{a}$ & $\mathrm{H} 2-3 \mathrm{a}$ & 75 & 15 & R4-4a & R5-2b & H3-1b & H3-2a \\
\hline 34 & 9 & R2-1a & R3-6a & $\mathrm{H} 2-1 \mathrm{~b}$ & $\mathrm{H} 2-1 \mathrm{~b}$ & 76 & 15 & R4-5a & R5-1a & H3-1a & $\mathrm{H} 3-3 \mathrm{a}$ \\
\hline 35 & 9 & $R 2-5 b$ & R3-5b & $\mathrm{H} 2-1 \mathrm{a}$ & $\mathrm{H} 2-3 \mathrm{~b}$ & 77 & 16 & R5-1a & R5-1a & H3-1a & H3-3a \\
\hline 36 & 9 & $\mathrm{R} 2-6 \mathrm{~b}$ & R3-5a & $\mathrm{H} 2-2 \mathrm{a}$ & $\mathrm{H} 2-4 \mathrm{a}$ & 78 & 16 & $\mathrm{R} 4-2 \mathrm{a}$ & $\mathrm{R} 4-2 \mathrm{a}$ & H4-1a & H4-1a \\
\hline 37 & 10 & $\mathrm{R} 3-5 \mathrm{a}$ & R3-5a & $\mathrm{H} 2-2 \mathrm{a}$ & $\mathrm{H} 2-4 \mathrm{a}$ & 79 & 16 & R5-2b & $\mathrm{R} 5-2 \mathrm{~b}$ & H3-1b & H3-2a \\
\hline 38 & 10 & R3-1a & R3-5a & $\mathrm{H} 2-2 \mathrm{a}$ & $\mathrm{H} 2-4 \mathrm{a}$ & 80 & 17 & R4-2a & R5-2a & H4-1a & H4-1a \\
\hline 39 & 10 & $\mathrm{R} 2-6 \mathrm{~b}$ & R4-6b & $\mathrm{H} 2-2 \mathrm{a}$ & $\mathrm{H} 2-4 \mathrm{a}$ & 81 & 18 & $\mathrm{R} 4-2 \mathrm{a}$ & R6-1a & H4-1a & H4-1a \\
\hline 40 & 10 & R3-2a & R3-5b & $\mathrm{H} 2-1 \mathrm{a}$ & $\mathrm{H} 2-3 \mathrm{~b}$ & 82 & 18 & R5-2a & R5-2a & $\mathrm{H} 4-1 \mathrm{a}$ & H4-1a \\
\hline 41 & 10 & R3-1b & R3-1b & $\mathrm{H} 2-3 \mathrm{a}$ & $\mathrm{H} 2-3 \mathrm{a}$ & 83 & 19 & R5-2a & R6-1a & H4-1a & H4-1a \\
\hline 42 & 10 & R3-5b & $\mathrm{R} 3-5 \mathrm{~b}$ & $\mathrm{H} 2-1 \mathrm{a}$ & $\mathrm{H} 2-3 \mathrm{~b}$ & 84 & 20 & R6-1a & R6-1a & H4-1a & H4-1a \\
\hline
\end{tabular}

